\title{
ANÁlise DO NEGÓCIO DA FINTECH DE PAGAMENTOS MÓVEIS SOB A PERSPECTIVA DO MODELO CANVAS
}

ANALYSIS OF THE BUSINESS OF THE MOBILE PAYMENT FINTECH BASED ON THE BUSINESS MODEL CANVAS PERSPECTIVE

\section{Sonia Rosa Arbues Decoster}

sonia.decoster@,fipecafi.org

Programa de Mestrado Profissional em Controladoria e Finanças da Faculdade Fipecafi

São Paulo/SP, Brasil

https://orcid.org/0000-0002-0081-347X

\section{Jessica Vasconcelos Guedes}

jessica.guedes@,fipecafi.edu.br

Programa de Mestrado Profissional em Controladoria e Finanças da Faculdade Fipecafi

São Paulo/SP, Brasil

https://orcid.org/0000-0002-0154-3168

\section{Resumo}

O objetivo deste estudo é analisar a proposta de valor das plataformas de pagamentos digitais móveis B2Be B2C, por meio do estudo de caso de uma fintech, líder mundial no segmento. As evidências empíricas foram coletadas a partir de análise documental da empresa objeto do estudo, da plataforma digital, entrevistas e contatos telefônicos em 2019. O instrumento de pesquisa foi elaborado a partir do referencial teórico das plataformas two sided network, bem como no Modelo Canvas - BMC. Por meio da análise de conteúdo foi possível evidenciar como a estratégia de adoção do modelo tecnológico inovador contínuo de pagamentos móveis se consolidou calcada na comunicação clara dos serviços propiciados para two-sided network.

Palavras-Chave: Fintech. Pagamentos digitais móveis. Proposta de valor. Modelos de negócios. Canvas.

\begin{abstract}
The objective of this study is to analyze the value proposition of the mobile digital payment platforms $\mathrm{B} 2 \mathrm{Be} \mathrm{B} 2 \mathrm{C}$, through the case study of a global fintech leader in the segment. The empirical evidence was gathered by analyzing the documents of the firm in the case study, the digital platform, interviews and phone calls in 2019. The research instrument was elaborated from theoretical background of the platforms two sided network and based on the Business Model Canvas - BMC. Through the content analysis it was possible to show how an adoption strategy of the continuous innovative technological model of mobile payments was consolidated based on clear communication of the services propitiated for two-sided network.
\end{abstract}

Keywords: Fintech. Mobile digital payments. Value proposition. Business model. Canvas 


\section{Introdução}

O cenário econômico mundial, em meio à pandemia do Covid-19, tem sofrido consequências gravíssimas desde o começo do ano de 2020, desencadeando grandes impactos na vida das pessoas e empresas. Para alguns analistas da OCDE, o mundo levará anos para se recuperar do impacto da pandemia, afirmando que o choque econômico já é maior do que a crise financeira de 2008 (Chan, 2020).

Acredita-se que a vida pós-pandemia não voltará a ser mesma do passado recente, pois, inversamente ao impacto da redução de atividades econômicas no mercado tradicional, uma mudança cultural passou a ocorrer no mundo. No Brasil, a realidade não é diferente. A aceleração da digitalização dos negócios impulsionada pela adoção de métodos eletrônicos de pagamentos por diversos pequenos empresários na comercialização de produtos e até mesmo serviços ocasionou uma popularização imediata das plataformas online para a venda de bens (Souza, 2020).

Segundo a $6^{a}$ edição da pesquisa "Perfil do E-Commerce Brasileiro", esse fenômeno causou um crescimento anual de 40,7\% no setor de lojas virtuais no país. Já são mais de 1,3 milhões de estabelecimentos online, sendo que 48,06\% deles se enquadram na categoria pequeno porte (com faturamento de até $\mathrm{R} \$ 250$ mil por ano). Em 2019, essa margem era de apenas 26,93\% do mercado brasileiro (Souza, 2020). Da mesma forma que houve um crescimento do trabalho em bome office, as compras online tornaram-se frequentes, e consequentemente os pagamentos digitais. Para as fintechs $s^{i}$, esse cenário tende a ser bastante positivo. Afinal, as transações online devem aumentar. Vale lembrar ainda que os bancos e as instituições digitais ganharam novos adeptos durante a pandemia (E-investidor, 2020).

Conforme pesquisa Ibope encomendada pelo C6 Bank, 46\% dos brasileiros das classes A, B e C com acesso à internet afirmam que têm utilizado produtos financeiros digitais com mais frequência. Do total, 43\% afirmaram que deixaram de frequentar agências bancárias, e 31\% contaram que a maior parte das compras passou a ser feita online (Tauhata, 2020). De outro lado, as fintechs dadas suas proposições inovativas e/ou disruptivas conseguem atingir consumidores de produtos e serviços que se encontram à margem dos produtos e serviços tradicionais, oferecendo-lhes alternativas viáveis e com efetiva entrega de valor (Gomber, Koch \& Siering, 2017; Gomber, Kauffman, Parker \& Weber, 2018).

Com o uso diário de smartphones, serviços bancários e comerciais baseados em aplicativos têm crescido, e as fintechs têm emergido em resposta a esta tendência (Dahlberg, Guo \& Ondrus, 2015). Nesse sentido, a atuação das fintechs terá papel fundamental no sentido de contribuir com a sobrevivência de diversas empresas e famílias brasileiras. É neste panorama que as fintechs podem se sobressair, uma vez que elas contam com tecnologias e recursos que conseguem prover acesso a uma população estimada em 45 milhões de pessoas e que movimentam anualmente mais de $\mathrm{R} \$ 800$ bilhões, mas que estão à margem das operações em bancos tradicionais (Infomoney, 2019).

O serviço mais popular entre as várias categorias de fintechs é o serviço de pagamento móvel, o qual seria o método de pagamento que faz uso do equipamento móvel para pagar e transferir dinheiro, e tem a vantagem da conveniência de infraestrutura sem fio podendo também ser utilizada a qualquer tempo e lugar (Iman, 2018). Adicionalmente, os pagamentos móveis têm se apresentado como uma alternativa promissora no declínio do uso do dinheiro e têm se proposto como uma solução para o acionamento do mercado eletrônico (Ondrus \& Pigneur, 2006). Menke e Lussanet (2006) argumentam que serviços de pagamentos móveis têm sido um sucesso no mercado eletrônico. Com isto em vista, as fintechs inovadoras passaram a se concentrar na entrega de soluções inovativas para problemas de clientes específicos (Loebbecke \& Picot, 2015).

Dentre a gama de serviços de pagamentos móveis encontram-se as multiplataformas digitais (Reuver, Verschuur, Nikayin, Cerpa \& Bouwman, 2015; Kauffman \& Ma, 2015), as quais são gerenciadas por uma plataforma provedora que visa facilitar transações por meio de alguns tipos de mediação de tecnologia 
digital (Stabell \& Fjeldstad, 1998) entre dois ou mais tipos distintos de usuários de plataformas, permitindo criar valor para todos.

As multiplataformas enfrentam o desafio crescente que é criar uma massa crítica de usuários e assim desencadear os efeitos potenciais de rede (Hagiu \& Rothman, 2016), de forma que como os pagamentos móveis são vistos como plataformas dentro de um ecossistema mais vasto de fintechs, não fogem a esta regra (Kauffman \& Ma, 2015; Milian, Spinola \& Carvalho, 2019).Mallat (2007) salienta a importância das externalidades de rede, enquanto Apanasevic, Markendahl e Arvidsson, (2016) indicam que a incapacidade de alcançar a massa crítica constitui a razão para o fracasso no serviço de pagamentos móveis. Portanto, a adoção simultânea de pagamentos móveis pelos consumidores (B2C) e varejistas (B2B), tem sido identificada como uma chave para o sucesso das plataformas móveis (Rochet \& Tirole, 2003).

Porém, a governança de diferentes atores, tais como varejistas e parceiros locais de pagamentos do ecossistema traz uma complexidade inerente à dinâmica de plataforma digital (Reuver et al. 2015; Iman, 2018) e constitui uma das fontes de desafios para os provedores de plataformas de pagamentos móveis (Dahlberg et al., 2015).Além disso, a complexidade pode ser um impeditivo para o crescimento destas plataformas de pagamentos móveis, pois o sucesso está na exequibilidade de seu modelo de negócios por parte do provedor (Iman, 2018). O que não é facilmente atingível uma vez que as fintechs tendem a se engajar em modelos de negócios que combinam soluções de pagamentos com as necessidades de clientes (Weichert, 2017).

O modelo de negócios é uma perspectiva crucial para o entendimento dos benefícios de cada stakeholder do ecossistema, onde a criação de valor e a captura de valor devem ser consideradas simultaneamente (Zott, Amit \& Massa, 2011). A difusão de uma inovação digital somente ocorrerá com sucesso se o modelo de negócios para esta inovação fornece oportunidades sólidas para a criação e captura de valor (Zott et al. 2011).

Portanto, à luz dos elementos previamente contextualizados o objetivo deste estudo é compreender como se dá a criação de valor e, consequentemente a proposta de valor de uma fintech de pagamento móvel que contribui para a obtenção e manutenção de massa crítica de participantes, levando ao alcance dos benefícios dos efeitos de rede de dois lados entre o B2B e o B2C. De forma específica, o estudo pretende contribuir com o conhecimento de como o modelo de negócios de caráter inovador fornece oportunidades sólidas para a criação e captura de valor por parte de uma fintech, ou seja, procura direcionar para uma estratégia de sucesso das fintechs, pois o mergulho neste tema apresenta uma alternativa para o momento que o Brasil está vivendo e continuará vivendo por um período no que tange à crise da pandemia do COVID-19.

Para tanto a questão que norteará esta pesquisa será: Como as multiplataformas provedoras de pagamentos móveis criam e oferecem uma proposta de valor em seus modelos de negócios com o intuito de assegurar massa crítica de participantes nos mercados B2B e B2C? A fim de avaliar empiricamente as proposições teóricas desenvolvidas nesta pesquisa foi realizado um estudo de caso em uma multiplataforma de pagamentos, a PayPal, empresa líder em pagamentos móveis por meio da realização de entrevistas, observação e análise de documentos.

Valendo-se de um modelo de pesquisa elaborado com base no referencial das plataformas de múltiplas faces de um mercado que tem como essência uma modelagem de negócios numa perspectiva de modelo centrado em rede, bem como o de criação, captura e proposta de valor de modelos de negócios proporcionados pelo Modelo Canvas - BMC, de Osterwalder e Pigneur (2011), com destaque para o impacto das fontes potenciais da criação de valor de negócios virtuais, foram evidenciados os desafios e as inovações que emergem na busca das soluções. 
Este trabalho está estruturado da seguinte forma: no próximo capítulo é descrita a fundamentação teórica a respeito das fintechs, plataformas digitais, modelos de negócios e o BMC - Business Model Canvas; no terceiro capítulo, destaca-se os procedimentos metodológicos utilizados para o alcance do objetivo proposto; no quarto capítulo, os dados coletados do caso e sua respectiva análise são apresentados, bem como o Modelo Canvas aplicado ao caso estudado é discutido e, por fim, no último capítulo, considerações finais são apresentadas com as limitações da pesquisa apontadas e sugestões para futuras pesquisas.

\section{Desenvolvimento teórico}

O termo fintech, derivado da contração das palavras finanças e tecnologia surgiu na literatura científica em 1972, como um acrônimo que significa "financial technology", combinando a expertise bancária com técnicas da ciência da moderna gestão e o computador (Bettinger, 1972, p. 62). Milian et al (2019) salienta que vários estudos consideram que as fintechs podem ser classificadas em duas categorias, baseando-se na teoria da inovação disruptiva de Christensen (2003),: 1) " fintechs sustentáveis", por provedores de serviços financeiros estabelecidos que trabalham para proteger suas posições de mercado fazendo uso de TI por meio de inovações incrementais e, 2) “ fintechs disruptivas" que são novas empresas e startups que desafiam provedores estabelecidos ao oferecer novos produtos e serviços (Chiu, 2016).

Segundo revisão sistemática da literatura providenciada por Milian et al. (2019), a quantidade de publicações a respeito de fintechs na literatura vem crescendo a cada ano, e especialmente desde 2016, mostrando o interesse da academia neste tema. A revisão em questão pesquisou o conjunto de definições para o termo fintech em direção a um consenso e sugere um entendimento abrangente do termo que concilie empresas inovadoras na indústria financeira que faz uso da disponibilidade de canais de comunicação, da ubiquidade da internet e do processamento automatizado da informação.

De acordo Gomber et al. (2017), os tradicionais players de serviços bancários e financeiros enfrentam uma transformação substancial com o crescimento dos serviços financeiros, e salientam que há três principais razões para isto ocorrer. Primeiro, as fintechs oferecem novos produtos e soluções que satisfazem as necessidades dos clientes, os quais, anteriormente, não eram suficientemente bem atendidos. Segundo, as fintechs criam novas oportunidades para serviços e produtos por meio da aplicação de novas tecnologias e novos conceitos. Terceiro, as fintechs se concentram em modelos de negócios baseados na internet, os quais são acessíveis e lucrativos e são suficientemente ágeis e inovativos que colocam os competidores estabelecidos sobre pressão.

Segundo Weichert (2017), atualmente, as fintechs desempenham em todo mundo um papel importante na utilização das novas tecnologias e novos modelos de negócios para assegurar um melhor alinhamento das soluções de pagamentos com as necessidades do cliente, impactando o amplo cenário dos serviços financeiros por grandes mudanças tais como: o comércio do princípio ao fim, avanços em machine learning $e$ analytics, personalização em massa com fidelidade, segmentação e novas proposições de valor, e por fim, transformações em conectividade, eficiência e segurança. Conforme o Relatório Global (2019) sobre Fintechs da CBInsights, que apresenta o panorama mundial, as fintechs atuam nos segmentos relacionados na Figura 1. 
Segmentos

Descrição

Créditos

Créditos comerciais e plataformas alternativas.

\begin{tabular}{|c|c|}
\hline 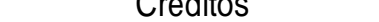 & \\
\hline Pagamentos & $\begin{array}{l}\text { Processamento de pagamentos, desenvolvedores de cartões, } \\
\text { ferramentas de software para faturamento. }\end{array}$ \\
\hline Finanças pessoais & Ferramentas para administrar contas e/ou contas de crédito, rastreamento pessoal. \\
\hline Transferências e remessas & Transferência internacional de dinheiro e software de rastreamento. \\
\hline Blockchain e criptomoedas & Companhias que alavancam tecnologias de blockchain para serviços financeiros. \\
\hline Mercado de capitais & $\begin{array}{l}\text { Ferramentas para instituições financeiras, tais como bancos, fundos, hedge, fundos } \\
\text { mútuos ou outros investidores institucionais. }\end{array}$ \\
\hline Hipoteca imobiliária & Crédito hipotecário e plataformas financeiras digitais. \\
\hline Gestão de patrimônio & Software para auditoria, risco e compliance. \\
\hline Regtech & Empresas que vendem ou fornecem seguros digitalmente. \\
\hline Seguros & Data analytics e software para seguradoras e resseguradoras. \\
\hline
\end{tabular}

Figura 1 Segmentos que as fintechs atuam e a sua descrição conforme Global Fintech Report Q1/2019

Fonte: Global State Of Fintech: Investment \& Sector Trends To Watch.(2019).

https://www.cbinsights.com/reports/CB-Insights Fintech-Report-Q4-2019.pdf. Recuperado em 20/05/2020.

\section{As fintechs no panorama atual brasileiro}

Segundo o Banco Central do Brasil (2020), as fintechs são empresas que introduzem inovações nos mercados financeiros por meio do uso intenso de tecnologia com potencial para criação de novos modelos de negócios. Atuam por meio de plataformas online, oferecem serviços digitais inovadores relacionados ao setor e, no Brasil, as fintechs estão regulamentadas desde abril de 2018 pelo Conselho Monetário Nacional (CMN) - Resoluções 4.656 e 4.657.

O Bacen (2020) apresenta em seu site institucional as seguintes categorias de fintechs: de crédito, de pagamento, gestão financeira, empréstimo, investimento, financiamento, seguro, negociação de dívidas, câmbio e multisserviços. Ainda, conforme o Bacen (2020), podem ser autorizadas a funcionar no país dois tipos de fintechs de crédito - para intermediação entre credores e devedores por meio de negociações realizadas em meio eletrônico: a Sociedade de Crédito Direto (SCD) e a Sociedade de Empréstimo entre Pessoas (SEP), cujas operações constarão do Sistema de Informações de Créditos (SCR).

As fintechs brasileiras são majoritariamente startups que trabalham para inovar e otimizar serviços do sistema financeiro, sendo que são apresentadas em várias categorias e, dentre elas, encontram-se as fintechs que permitem pagamentos digitais e móveis em qualquer plataforma e por meio de qualquer dispositivo, podendo efetuar pagamentos e recebimentos sem tarifas, bem como as fintechs de crédito que tem como objetivo oferecer crédito de modo fácil e rápido, além de serem menos burocráticas em relação às instituições financeiras. Estas empresas representam uma saída, tanto para aquelas pessoas sem conta em banco que necessitam da aprovação para realizar empréstimos de dinheiro ou, simplesmente, possibilitar acesso a crédito para as pequenas, médias e micro empresas (Pesquisa Sebrae, 2018).

Segundo pesquisa realizada pelo Sebrae (2018) em parceria com a Associação Brasileira de Fintechs, a ABFintechs, numa amostra de 295 fintechs, $84 \%$ das empresas pesquisadas demonstraram interesse em desenvolver produtos e serviços específicos às necessidades das micro e pequenas empresas. A maior parte das fintechs foca em produtos e serviços que são justamente as maiores demandas não atendidas dos pequenos negócios no sistema financeiro. Segundo esta pesquisa de 2018, os segmentos que as fintechs atuam no Brasil são os demonstrados na Figura 2. 


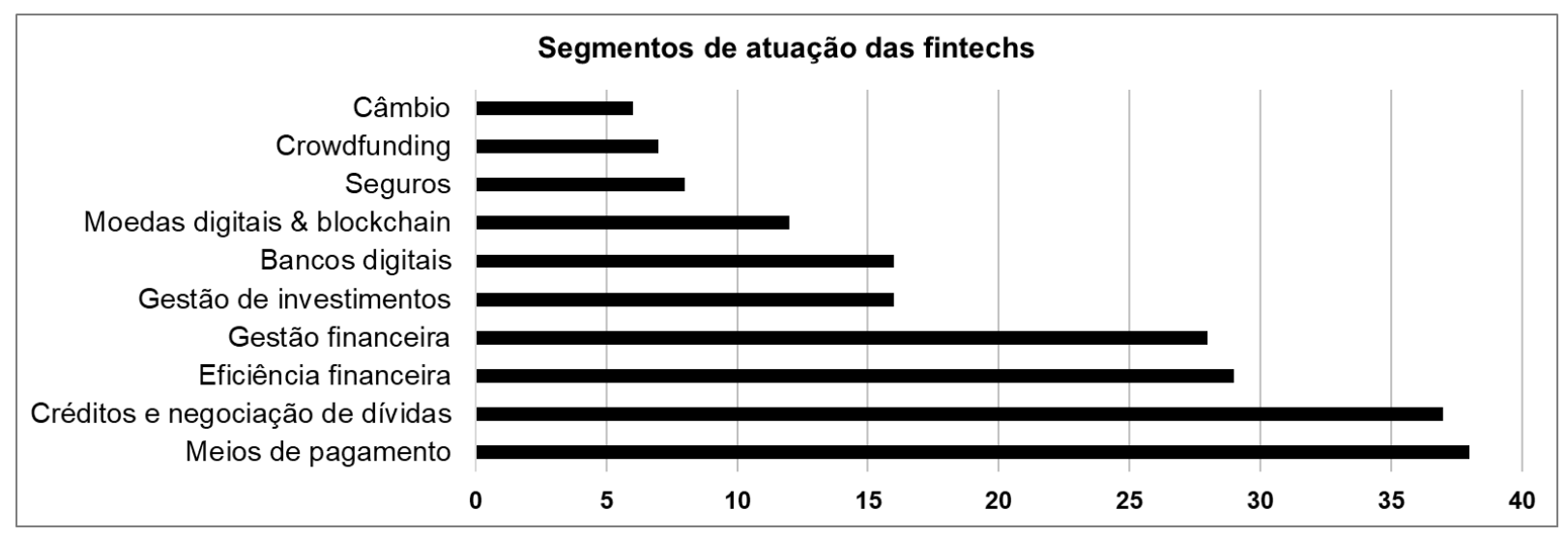

Figura 2. Pesquisa Sebrae (As Fintechs e os Pequenos Negócios)

Fonte: Sebrae (2018). As Fintechs e os Pequenos Negócios. LAB - Laboratório de Inovação Financeira ABDE/BID/CVM. Recuperado em 20 de maio, 2020.

https://www.sebrae.com.br/Sebrae/Portal\%20Sebrae/Anexos/FintecsMPE 13.9.2018.pdf.

\section{A fintech de serviço de pagamento móvel - as plataformas digitais.}

A revolução nos serviços financeiros foi anunciada a partir da vertiginosa adoção e expansão dos smartphones, os quais passaram a incorporar pagamentos. O pagamento móvel passou a funcionar como uma plataforma digital apresentando características muito diferentes de inovações anteriores na área financeira (Kazan \& Damsgaard, 2013). A digitalização de serviços reduziu expressivamente as barreiras de entrada, pois as soluções digitais possuem significativas economias de escala e facilitam a sua replicação com custos muito baixos. A escalabilidade da plataforma digital intensifica a competição de diferentes provedores de pagamentos permitindo a obtenção de vantagem competitiva na área de pagamentos digitais (Staykova \& Damsgaard, 2015).

Podemos definir o negócio de um provedor de pagamentos móveis como o de uma plataforma que intermedia transações entre dois grupos de clientes diferentes e apropriadamente cobra de cada um (Staykova \& Damsgaard, 2015). Para um provedor de pagamentos obter sucesso deve possuir a habilidade de atrair clientes em quantidade suficiente nos diferentes lados da plataforma de forma pontual e, simultaneamente cultivar relacionamentos com clientes de cada um dos lados (Ondrus, Gannamaneni \& Lyytinen, 2015).

A partir destes acontecimentos, o surgimento de um campo de pesquisa novo se deu para acomodar todas as peculiaridades de modelos de negócios, permitindo o estudo de plataformas de transações que trazem múltiplas lados ou faces de um mercado (Thomas, Autio \& Gann, 2014). Segundo a literatura, uma plataforma tem como essência uma modelagem de negócios que pode apresentar perspectivas diferenciadas, e dentre várias, destacam-se o modelo de inovação aberta (Chesbrough, 2006), o modelo como um ecossistema (Van der Borgh, Cloodt \& Romme, 2012), ou como modelo centrado em rede (Laya, Markendahl \& Lundberg, 2018).

No caso do contexto em rede, alguns autores especificam perguntas como dimensões para representar o modelo de negócio (Ikävalko, Turkama, \& Smedlund, 2018) neste contexto, tais como; who (quem), what (o quê), how (como) e why (porquê). A primeira questão seria o who, que refere-se aos autores que fazem parte do modelo de negócios em rede, bem como os seus papéis e valores; what, seria a proposta de valor que a rede configurada de atores desenvolve e entrega valor para os clientes ( Palo \& Tähtinen, 2011); how é a perspectiva de atividades, onde o modelo de negócios é visto como um mecanismo organizacional para formatar e coordenar atividades para criar valor para os clientes e para a rede (Palo \& Tähtinen, 2013) e, why seria o alcance dos objetivos estratégicos comuns que faz com que as organizações em um mundo digital e conectado dependam uma das outras integrando valor entre os participantes da rede, bem como os processos e as atividades relacionados ao valor (Ziouvelou \& 
McGroarty, 2018), enfim uma ferramenta de gestão para verificar e controlar a distribuição de valor com uma criação conjunta de valor (Wirtz., Pistoia, Ullrich, \& Göttel, 2016).

\section{As redes de dois lados ou faces (two-sided networks)}

Conforme Eisenmann, Parker, Van Alstyne e Marshall (2006), a mais importante inovação em serviços financeiros desde a $2^{\text {a }}$. Guerra Mundial são os cartões de crédito, os quais conectam comerciantes e consumidores. Eles fornecem produtos e serviços que trazem conjuntamente grupos de usuários em dois lados da rede denominados de plataformas. Com relação à Internet, a maior parte dos negócios são de fato plataformas intermediárias de dois lados ou multiplataformas, sejam oriundas de plataformas de redes sociais que conectam usuários com provedores de vários serviços ou aplicações, bem como plataforma de e-commerce, a qual traz compradores e vendedores, ou ainda plataformas de buscas, as quais conectam usuários e anunciantes.

Estas plataformas tipicamente apresentam dois tipos de participantes (ou lados): o lado do negócio (B2B), o qual frequentemente que paga o serviço e o lado do consumidor do serviço (B2C), o qual pode ou não pagar pelo serviço. Em cada caso, cada lado geralmente origina de externalidades positivas vindas da participação de membros do outro lado (Muzellec, Ronteau \& Lambkin, 2015).

As redes de dois lados ou faces (two-sided networks) podem ser encontradas em muitas indústrias, compartilhando o espaço com produtos tradicionais e oferta de serviços. Entretanto as redes de dois lados ou faces diferem de outras ofertas em uma fundamental maneira. $\mathrm{Na}$ tradicional cadeia de valor, o valor move da esquerda para direita, onde a esquerda é o custo e a direita é a receita. Em redes de dois lados ou faces, o custo e a receita estão na esquerda e na direita, em virtude da plataforma ter um grupo distinto de usuários em cada lado. A plataforma incorre em custos servindo ambos os grupos e pode coletar receita de cada, embora um dos lados frequentemente ser subsidiado (Jocevski, Ghezzib \& Arvidsson, 2020).

Alcançar uma massa crítica de clientes de cada lado é primordial para a plataforma e para a criação de um efeito de rede positivo como um alicerce de um modelo de negócios da plataforma (Rochet \& Tirole, 2003). O efeito da externalidade da rede é determinado quando a participação se torna atrativa para cada indivíduo quando outros começam a participar da rede (Rohlfs, 1974). Segundo Parker, Van Alstyne e Choudary (2016), os efeitos da rede de uma plataforma podem ser positivos ou negativos. Os positivos ocorrem quando a plataforma possibilita trocas significativas de valor para todos os usuários da comunidade que ela rege e, nesse caso, a vantagem competitiva será ampliada. O efeito negativo acontece quando há dificuldades ou interrupções no relacionamento entre os atores da rede.

Segundo Hagiu e Wright (2015), quando diferentes clientes afiliados a uma plataforma aderem à plataforma baseada em um número de clientes no mesmo grupo (efeito direto) ou em outro de grupo de clientes distintos (efeitos indiretos), o efeito de rede cresce e a plataforma torna-se valiosa e viável. Argumenta-se também que ao alcançar a massa crítica torna-se dependente de um modelo de negócios de um provedor de pagamentos móveis, bem como em ações de parceiros facilitadores da infraestrutura de pagamento (Iman, 2018).

Portanto, estudar um provedor de pagamento móvel leva ao ao entendimento de formas de inovações em modelo de negócios que pode ser aproveitado para o enfrentamento de desafios concernentes ao estágio inicial e alcance da massa crítica (Staykova \& Damsgaard, 2016). Adicionalmente, o relacionamento de clientes que um provedor de pagamentos móveis tem com cada um dos clientes de grupos desempenha um papel vital na viabilidade de uma plataforma própria (Ondrus \& Lyytinen, 2011).

\section{Modelo de negócio virtual (e-business)}

Orofino (2011) enfatiza que o termo de modelo de negócios é recente e ganha evidência a partir da década de 90 por conta do advento da internet e do surgimento das empresas "ponto com". Podemos 
definir modelo de negócios ao assimilar a lógica de criar, entregar e capturar valor para a organização (Osterwalder \& Pigneur, 2011) a partir de uma plataforma que conecta os recursos, processos e fornecedores da empresa (Nielsen \& Lund, 2015). Casadesus-Masanell e Ricart (2010) exemplificam como a forma que a organização cria e entrega valor aos seus stakeholders. Outros autores procuraram definir modelo de negócios mediante uma ótica distinta, porém é possível identificar a existência de ponto em comum entre os diferentes autores ao justificar que a conceituação de modelo de negócio estruturase essencialmente nos fundamentos da criação e captura de valor por parte da organização.

No caso de negócios virtuais (e-business), Amit e Zott (2001) conceituam como a estrutura é elaborada para a criação de valor, salientando que há quatro fontes potenciais identificadas, denominadas como eficiência, complementaridade, lock-in e caráter inovador (Figura 3). Sugerem que há uma integração de vários modelos baseados em lentes teóricas encontradas no campo de gerenciamento estratégico e empreendedorismo, tais como análise de cadeia de valor, a teoria de inovação "Shumpeteriana", a teoria VBR (visão baseada em recursos), teoria de redes, e a teoria de custos de transações econômicas. E acrescentam que há uma interdependência entre as fontes de valor e a localização da criação de valor no e-business, de forma que a presença de cada condutor de valor pode reforçar a eficácia de outro qualquer.

\begin{tabular}{|c|c|}
\hline Eficiência & $\begin{array}{l}\text { A eficiência nos negócios online pode ser realizada de várias maneiras, tal como reduzir as } \\
\text { informações assimétricas entre compradores e vendedores por meio de fornecimento } \\
\text { atualizado de informação abrangente. A velocidade e a facilidade que cada informação pode } \\
\text { ser transmitida via internet faz a abordagem tornar-se fácil e conveniente. Por alavancar a } \\
\text { interconectividade barata dos mercados virtuais, o e-business intensifica a eficiência da } \\
\text { transação por permitindo agilizar a tomada de decisão. }\end{array}$ \\
\hline Complementaridades & $\begin{array}{l}\text { Estão presentes sempre que tiver um grupo de mercadorias que em conjunto fornece mais } \\
\text { valor que o valor total de cada uma separadamente. A teoria RBV também evidencia o } \\
\text { papel das complementaridades entre ativos estratégicos como uma fonte de criação de } \\
\text { valor (Amit \& Schoemaker, 1993); e a teoria de rede destaca a importância das } \\
\text { complementaridades entre os participantes em uma rede (Gulati, 1999). }\end{array}$ \\
\hline Lock-in & $\begin{array}{l}\text { O potencial de criação de valor de um e-business é evidenciado pela extensão de quais } \\
\text { clientes são motivados em se engajar em transações repetidas (o qual tende a aumentar o } \\
\text { volume de transações), e por extensão para aqueles parceiros estratégicos que tem } \\
\text { incentivos para manter e melhorar as suas associações, que pode resultar na disponibilidade } \\
\text { aumentada em pagar dos clientes e baixos custos de oportunidade para as empresas. Lock- } \\
\text { in é manifestado como custos de transferências, que está ancorado no modelo de custos de } \\
\text { transação de Williamson (1979) e nas externalidades de rede, o qual tem suas raízes na } \\
\text { teoria de redes (Katz \& Shapiro, 1985). E, como a teoria RBV sugere, ativos estratégicos } \\
\text { da firma, tais como marca, a relação de confiança comprador-vendedor, ambos contribuem } \\
\text { para o Lock-in. O e-business frequentemente conecta terceiros que participam em transações } \\
\text { comerciais, os quais são considerados geradores de redes. Redes podem exibir } \\
\text { externalidades em que as atividades de produção e consumo de um terceiro conectado a } \\
\text { rede tem um efeito nas funções de utilidade ou produção de outros participantes na rede. } \\
\text { Este efeito não é transmitido por meio de mecanismo de preço. }\end{array}$ \\
\hline Caráter Inovador & $\begin{array}{l}\text { A potencial criação de valor de inovações tem sido articulado por Schumpeter (1934). E- } \\
\text { businesses inovam em muitas maneiras em fazer seus negócios na estruturação de transações. } \\
\text { As características únicas de mercados virtuais, onde há a remoção de limites físicos e } \\
\text { geográficos, a possível inversão de fluxos de informação de clientes para vendedores faz as } \\
\text { possibilidades para inovação parecer sem fim. }\end{array}$ \\
\hline
\end{tabular}

Figura 3 Fontes potenciais da criação de valor de negócios virtuais

Fonte: Amit, R.\& Zott, C., (2001), Value Creation in E-business. Strategic Management Journal, 22, 493-520.

A proposta de valor é o coração dos modelos de negócios (Osterwalder \& Pigneur, 2011), podendo ser definida como um conjunto de práticas de comercialização empregadas para elaborar sugestões sobre como as capacidades de provedores, definidas como soluções, possibilitam os clientes a criar valor (Storbacka, 2011). Daí que, a base fundamental dos negócios na internet é a proposta de valor oferecida aos consumidores, de um lado, e para os fornecedores de negócios de outro lado. Atualmente, uma abordagem em modelos negócios é mais difundida de maneira que os negócios virtuais bem construídos 
identificam o público alvo de consumidores e uma proposta clara de valor, pois especificam a estrutura de cadeia de valor, o mecanismo de geração de receita, uma estrutura de custos estimada, bem como a potencial lucratividade de seu negócio (Chesbrough, 2010).

\section{Business Model Canvas - BMC}

O Business Model Canvas, ou simplesmente conhecido como Canvas, é uma ferramenta visual que tem como objetivo ajudar a desenvolver e estruturar negócios (Osterwalder \& Pigneur, 2011). Segundo Dorf e Blank (2012), o "Business Model Canvas (BMC)", é uma importante ferramenta de gerenciamento estratégico, auxiliando no desenvolvimento de esboços e versões finais de modelos de negócio, tanto para um novo empreendimento quanto para uma empresa que já está na ativa. É composto de nove dimensões que cobrem os três pilares conceituais da definição de modelo de negócios e que juntas fornecem ao empreendedor/gestor uma visão geral da empresa.: criação de valor (parcerias-chave, atividades-chave e recursos-chave); entrega de valor (canais, segmento de clientes e relacionamentos com o cliente); e captura de valor (estrutura de custo e fontes de receitas), além da proposta de valor, conforme evidenciado na Figura 3.

Em virtude de ser uma ferramenta visual, o Canvas pode facilitar a discussão, o debate e a exploração de potenciais inovações para o modelo de negócios com os usuários construindo e desenvolvendo uma perspectiva sistêmica de uma organização e destacando o impacto da criação de valor (Wallin, Chirumalla \& Thompson, 2013; Bocken, Short, Rana \& Evans, 2014). O Canvas tem sido adotado por profissionais distintos (Nordic Innovation, 2012; Kaplan, 2012) e pesquisadores (Abraham, 2013; Massa \& Tucci, 2014).

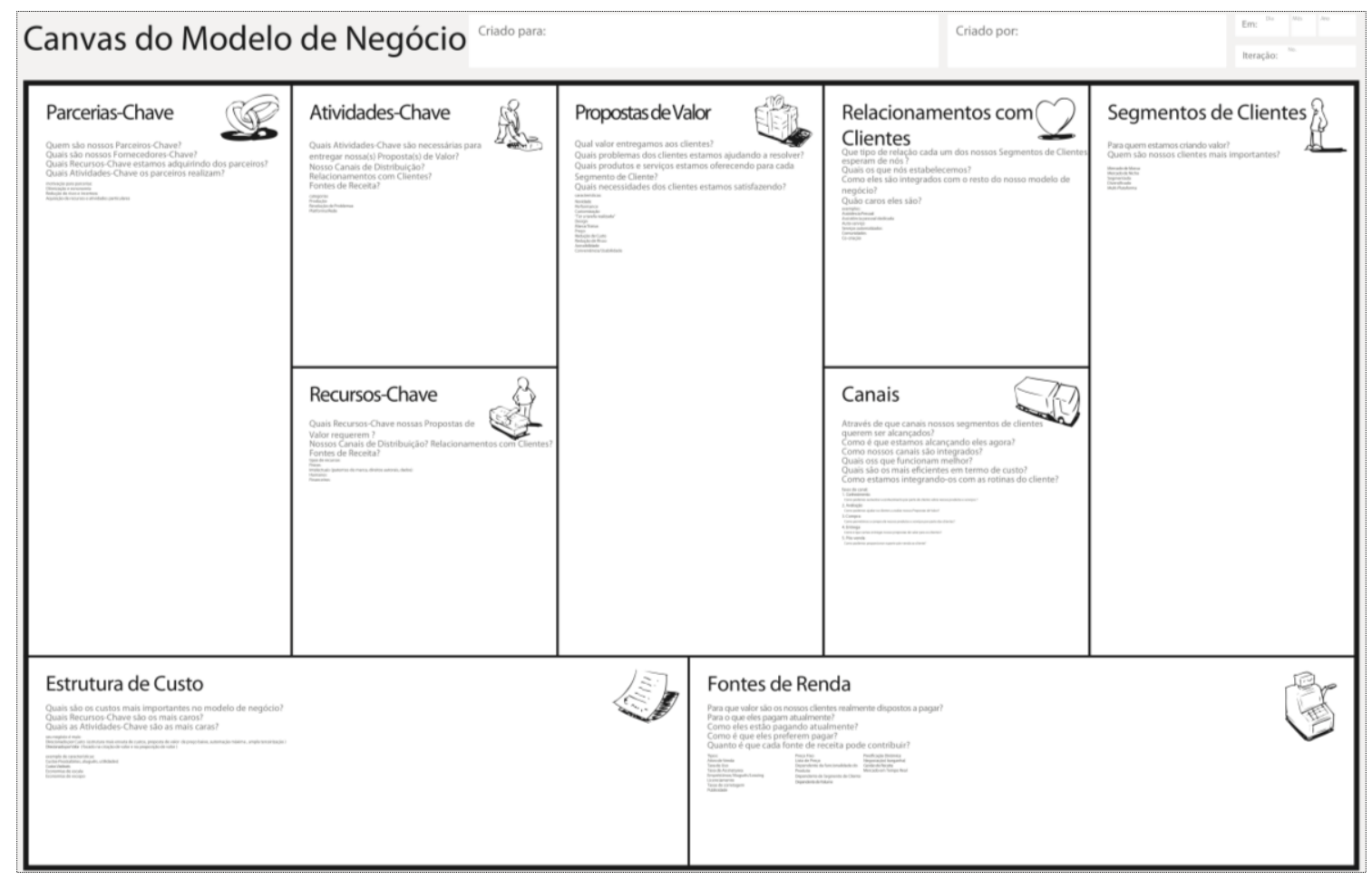

\section{Figura 4 Business Model Canvas}

Fonte: Osterwalder, A. \& Pigneur, Y., (2011). Business Model Generation: Inovação Em Modelos De Negócios. São Paulo: Alta Books Editora. Recuperado em 10 de maio, 2020, de https://pt.wikipedia.org/wiki/Business Model Canvas. 


\section{Os nove componentes do Modelo Canvas}

São nove os elementos que compõem ao Modelo Canvas, desenvolvidos para ajudar a compreender o processo funcional de cada variável de que faz parte o modelo de negócio implantado. Segundo Osterwalder \& Pigneur (2011), estes elementos que compõem o modelo são considerados como principais partes da modelagem de negócios, conforme descrito no quadro 1.

\begin{tabular}{|c|c|}
\hline $\begin{array}{l}\text { Segmentos de } \\
\text { Clientes }\end{array}$ & $\begin{array}{l}\text { Osterwalder e Pigneur (2011) enfatizam a necessidade de conhecer quem são os clientes } \\
\text { que se pretende atingir, qual é o seu perfil, onde estão localizados e definir os diferentes } \\
\text { grupos de pessoas ou organizações que a empresa busca alcançar. }\end{array}$ \\
\hline $\begin{array}{l}\text { Proposta de } \\
\text { Valor }\end{array}$ & $\begin{array}{l}\text { Esse elemento reflete o valor de seu produto ou serviço na visão do cliente, ou seja, é o } \\
\text { motivo pelo qual os clientes escolhem uma empresa ou outra, satisfazendo a necessidade } \\
\text { do consumidor. Esta parte é a que destaca o processo e a estratégia do modelo, por ser } \\
\text { aquela que traz uma inovação genuína ou uma releitura de uma estratégia existente. }\end{array}$ \\
\hline Canais & $\begin{array}{l}\text { É o componente que apresenta como uma determinada empresa irá entregar a sua } \\
\text { proposta de valor, ou melhor, como o produto ou serviço deve chegar aos clientes. Os } \\
\text { autores procuram explanar que é importante definir a mistura adequada de canais para } \\
\text { que os clientes sejam satisfeitos, seja por canais particulares, que podem ser diretos, por } \\
\text { sites, ou de forma indireta, por revendas operadas pela organização. }\end{array}$ \\
\hline $\begin{array}{r}\text { Relaciona } \\
\text { com Cli }\end{array}$ & $\begin{array}{l}\text { Dentre os tipos de relacionamentos com os clientes destacam-se; 1) Assistência pessoal - } \\
\text { Baseada na interação humana, pela qual o cliente pode se comunicar diretamente com um } \\
\text { representante da organização para tirar dúvidas e auxiliar o mesmo com o produto ou } \\
\text { serviço, por ex., call Center, e-mail, entre outros; 2) Assistência pessoal dedicada - Baseia- } \\
\text { se na disponibilização de um representante da empresa para um cliente específico. 3) Self- } \\
\text { Service e 4) Serviço automatizado - baseia-se no relacionamento com clientes aos quais } \\
\text { as empresas não mantêm contato, porém, coloca à disposição todos os dispositivos que o } \\
\text { cliente precisará para a aquisição de seu produto e/ou serviço; 5) Cocriação - Baseia-se } \\
\text { em um tipo relacionamento inovador na relação cliente-vendedor, quando incentiva os } \\
\text { consumidores a divulgar suas opiniões. }\end{array}$ \\
\hline $\begin{array}{l}\text { Fonte } \\
\text { Rece }\end{array}$ & $\begin{array}{l}\text { Componente que determina o preço pago pelos clientes pelo produto e/ou serviço } \\
\text { entregue, descontando o custo do canal e do relacionamento com clientes. }\end{array}$ \\
\hline Recur & $\begin{array}{l}\text { Esse componente relaciona os recursos que permitem que a empresa crie e oferte sua } \\
\text { proposta de valor e que faz o modelo de negócio funcionar, que podem ser físicos, } \\
\text { financeiros, intelectuais ou humanos, sejam próprios ou alugados pela empresa ou } \\
\text { adquiridos de parceiros-chave. }\end{array}$ \\
\hline $\begin{array}{l}\text { Atividades- } \\
\text { chave }\end{array}$ & $\begin{array}{l}\text { As atividades-chave necessárias para o desenvolvimento de um modelo de negócio se } \\
\text { distinguem dependendo do modelo de negócio ao qual a organização está inserida, de } \\
\text { forma que a sua implementação dependerá da funcionalidade da empresa. }\end{array}$ \\
\hline Parcerias & $\begin{array}{l}\text { Aqui são relacionados os parceiros principais que põem o negócio para funcionar, que são } \\
\text { os fornecedores, as alianças estratégicas, a competição entre concorrentes por parceiros } \\
\text { melhores e a busca pelo desenvolvimento de novos negócios na descoberta de novos } \\
\text { parceiros }\end{array}$ \\
\hline Custos & $\begin{array}{l}\text { É a parte onde é descrito todos os gastos que são exigidos para o desenvolvimento do } \\
\text { negócio, seja um novo modelo ou a reestruturação de um modelo de negócio existente. } \\
\text { Este componente inclui os custos fixos, tais como salários, aluguéis, despesas com } \\
\text { manutenção, e os custos variáveis de comissões e taxas de venda ou distribuição do } \\
\text { produto. }\end{array}$ \\
\hline
\end{tabular}

\section{Figura 5 Os nove componentes do Modelo Canvas}

Fonte: Osterwalder, A. \& Pigneur, Y., (2011). Business Model Generation: Inovação Em Modelos De Negócios. São Paulo: Alta Books Editora

\section{Modelo de pesquisa Proposto}

Baseado no referencial teórico das plataformas de múltiplas faces de um mercado que tem como essência uma modelagem de negócios numa perspectiva de modelo centrado em rede, bem como o de criação, captura e proposta de valor de modelos de negócios proporcionados pelo Modelo Canvas - BMC, e destacando o impacto das fontes potenciais da criação de valor de negócios virtuais, o modelo de pesquisa foi elaborado pelos autores e apresentado na Figura 6. 


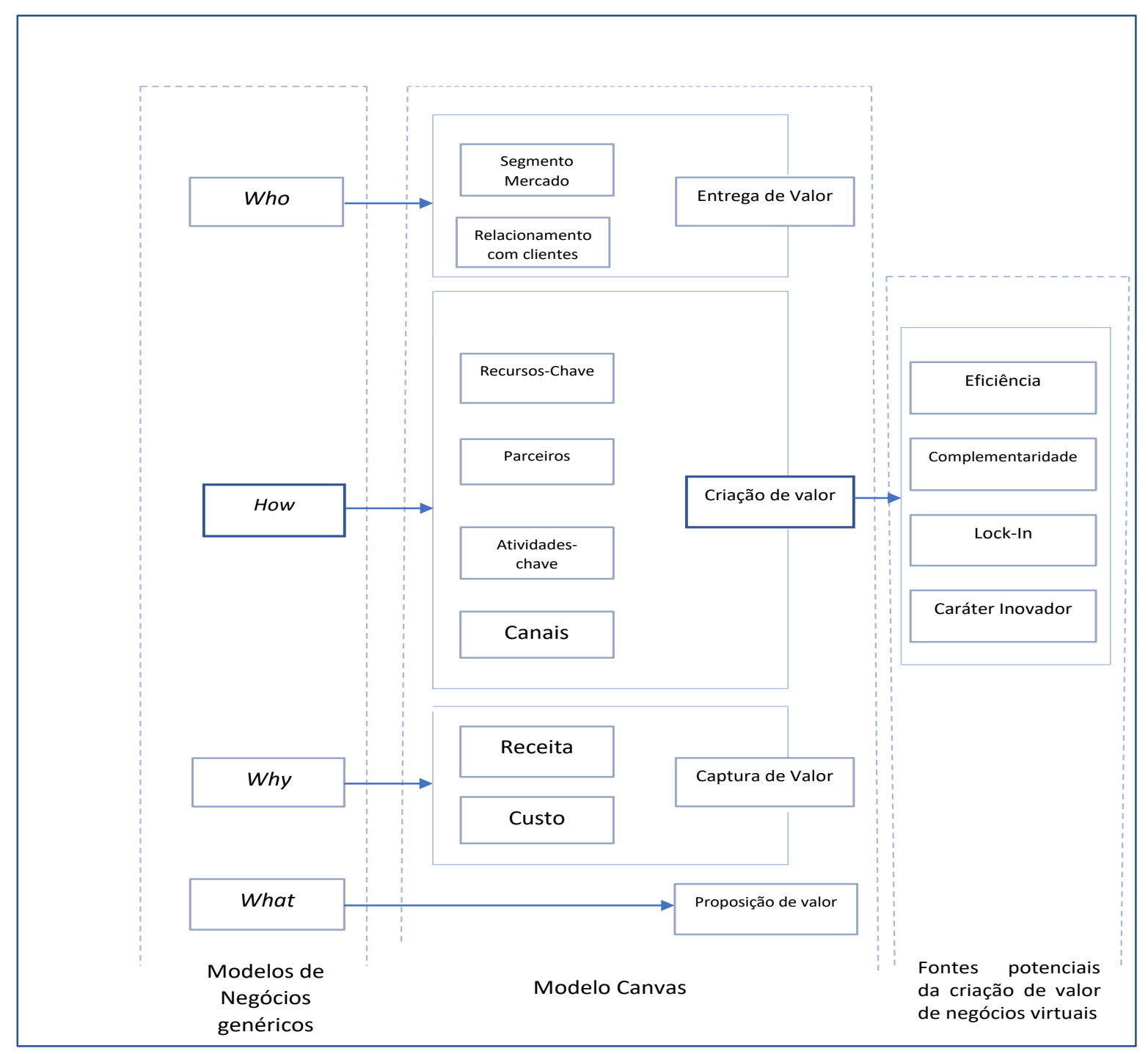

Figura 6 Modelo baseado no referencial teórico

Fonte: Elaborado pelos autores.

\section{Procedimentos metodológicos}

Este estudo é qualitativo de caráter exploratório e descritivo, e utiliza o método de estudo de caso. A primeira fase do estudo em questão exigiu uma etapa exploratória para definir com maior precisão obter dados adicionais do tema selecionado amplo e recém explorado. Essa etapa constituiu-se da revisão da literatura pertinente ao tema (em artigos acadêmicos, publicações em jornais, sites especializados, entidades do governo). O método na segunda fase é o estudo de caso único (Yin, 2009), por meio do uso de bases teóricas e o desenvolvimento de uma descrição do caso.

Apesar do entendimento comum de que um estudo de caso único não pode fornecer informações confiáveis para generalização, esse método é ideal como estratégia de pesquisa que possibilita maior profundidade de análise, o que pode evidenciar características especiais de modo que há crescente literatura que evidencia o valor do estudo de caso único (Dyer, Wilkins \& Eisenhardt, 1991; Langley, 1999). Segundo Gil (2009), nas ciências sociais aplicadas, a utilização de um caso único é possível quando o caso analisado apresenta singularidade, ou seja, quando uma empresa apresenta características particulares em sua caracterização. O caso em questão trata-se de uma empresa líder em plataforma de tecnologia que permite pagamentos digitais e móveis em nome de consumidores e comerciantes em todo 
o mundo. Segundo essa perspectiva, o conhecimento profundo de um caso pode auxiliar o pesquisador no entendimento de outras situações semelhantes.

\section{Coleta de Dados}

As evidências empíricas foram coletadas a partir de análise documental da empresa objeto do estudo de caso, da plataforma digital, entrevistas e contatos telefônicos durante de $2^{\circ}$ semestre de 2019 . O instrumento de coleta foi um roteiro semiestruturado de entrevista, elaborado a partir do protocolo de pesquisa, com o objetivo de "dar ao entrevistador flexibilidade para ordenar e formular as perguntas durante a entrevista” (Godoi, Bandeira-De-Melo \& Silva, 2010, p. 304), sendo aplicado ao CFO (Chief Financial Officer) da organização, procurando captar em profundidade a perspectiva do ator pesquisado.

\section{Roteiro da Entrevista / Lista de Tópicos}

O protocolo de entrevista cobriu três tópicos, conforme relacionado abaixo, concentrando-se principalmente em questões relacionadas ao modelo de negócios e seus elementos.

- Características da plataforma de pagamentos- referem-se às informações gerais sobre a plataforma de pagamentos Pay-Pal, stakeholders envolvidos e o papel dos negócios no ecossistema ao longo dos anos.

a. Ideias centrais em que se baseia o serviço de pagamentos e comparação com meios existentes de pagamentos e competidores.

b. O papel do provedor de pagamentos no ecossistema e suas particularidades

- Questões relacionadas ao modelo de negócio tendo como base o BMC de Osterwalder \& Pigneur (2011)

a. Captura, Criação, Entrega e Proposição de valor.

b. Abordagem de marketing de cada grupo de clientes.

c. Infraestrutura de pagamento e a tecnologia subjacente.

d. Aspectos financeiros, relacionados a estratégia de receita e de preço.

- Desenvolvimento futuro de ideias e expectativas em relação ao ecossistema de modelo de pagamentos, incluindo o relacionamento com os varejistas.

a. Iniciativas “omni-channel” ou seja, a respeito dos diferentes tipos de canais de varejistas: computador, smartphone e loja física.

b. Próximos passos e tecnologias futuras da indústria de pagamentos.

\section{Figura 7 Roteiro de Entrevista}

Fonte: Osterwalder \& Pigneur(2011). Business Model Canvas e Amit, R.\& Zott, C., (2001), Value Creation in E-business

\section{Procedimento de Análise de Dados}

A entrevista, como fonte primária de dados, foi gravada, analisada e transcrita e submetida à análise de conteúdo (Bardin, 2006), de onde foi possível classificar e ordenar segundo as dimensões da criação de valor do modelo de negócio da fintech sob a perspectiva da abordagem "Business Model Canvas - BMC", tendo em vista que o valor é a unidade de análise de um modelo de negócio. Com o intuito de responder ao problema e aos objetivos que o artigo se propõe, os dados coletados foram analisados por meio da análise categorial que, segundo Bardin (2006), consiste no desmembramento do texto em categoriais agrupadas analogicamente. O processo de formação das categorias se concretizou da forma prevista por Bardin (2006), após a seleção do material e a leitura flutuante (pré-análise), e a exploração foi realizada por meio da codificação de dados, processo que se restringe à escolha de unidades de registro, ou seja, o recorte que se pretende na pesquisa. No caso deste estudo, a categorização teve como base os 9 elementos do Modelo Canvas. 


\section{Apresentação e análise dos resultados}

O provedor de pagamentos PayPal é provavelmente a fintech mais conhecida mundialmente, pois trata-se da empresa líder em plataforma de tecnologia que permite pagamentos digitais e móveis em nome de consumidores e comerciantes em todo o mundo. A empresa PayPal foi fundada em dezembro de 1998 como Confinity, uma empresa de softwares para dispositivos móveis. Em março de 2000, a Confinity se fundiu com a empresa X.com, uma companhia bancária online fundada por Elon Musk. Em julho de 2002 foi adquirida pelo site de compras online eBay, que havia incorporado a empresa de pagamentos online Billpoint três anos antes, tornando-se sua subsidiária.

Em 2010, a empresa tinha presença em 180 países e em 25 moedas correntes. O ${ }^{\mathrm{ii}}$ PayPal não se restringiu apenas ao eBay, sendo aceito desde registros de domínios, e-commerce até pagamentos de serviços de hospedagem de sites. Em 2015, o eBay anunciou que tornaria o PayPal uma empresa própria e a partir desde período, o PayPal lançou suas ações na bolsa de valores eletrônica NASDAQ (National Association of Securities Dealers Automated Quotations).

Em 2015, o PayPal cresceu aproximadamente 16\% ao ano, sendo que 52\% da receita do eBay era gerada através do PayPal, e em 2018, seu valor estimado de mercado passou a ser de US\$ 103 bilhões, 68 vezes o valor da sua compra 16 anos antes. A empresa possui aproximadamente 20.000 profissionais no mundo e opera em mais de 220 países. No Brasil, a sua entrada se deu em 2010 e a sua estrutura organizacional apresenta as áreas de planejamento financeiro, controladoria, contabilidade, tesouraria, tributos, tecnologia da informação (apenas parte de hadware, pois infraestrutura e cloud está localizada na matriz), e uma equipe interna especializada em fraudes, todos abaixo do CFO (Chief Financial Officer) da organização.

\section{O caso PayPal mediante a estrutura de valor do BMC}

O caso apresenta a sua descrição mediante os três pilares conceituais da definição de modelo de negócios Canvas, com o intuito de fornecer uma visão geral da empresa. As nove dimensões que cobrem os três pilares seguem detalhadas. O modelo visual foi desenvolvido inicialmente por meio de um protótipo online do Canvas disponibilizado pelo Sebrae (2013).

\section{BMC - Criação de Valor - Parceiros Chave}

- $\quad$ Plataformas Market-Place e E-commerce: Em dezembro de 2019, o PayPal e o Mercado Livre fecharam acordo comercial para ampliar a aceitação e o uso de suas carteiras digitais, atingindo quase 350 milhões de usuários em todo o mundo. No entanto, o contrato prevê que cada companhia opere de forma independente, mantendo suas próprias carteiras digitais. Desembolsou US\$ 750 milhões para adquirir ações ordinárias do Mercado Livre, e-commerce com forte atuação na América Latina, que desenvolveu a carteira digital Mercado Pago, fintech de serviços financeiros do Mercado Livre (Furlan, 2019).

- $\quad$ Empresas de Cartão de Crédito: As empresas de cartão de crédito entram em parceria com o PayPal para ampliar a opção de pagamento ao consumidor. Com a Visa, a parceria funciona trabalhando de forma mais colaborativa para acelerar a adoção de pagamentos digitais seguros, confiáveis e convenientes para consumidores e comerciantes. Segundo o CFO, "o acordo destina-se a trazer beneficios significativos para a emissão de instituiçoes financeiras, adquirentes e comerciantes, que implica em mais volume de gastos em seus cartões de crédito e débito, menores custos operacionais e maior segurança, 'iii. O PayPal e a Mastercard expandem parceria para beneficiar consumidores, comerciantes e instituições financeiras. O Masterpass é uma opção de pagamento para os comerciantes que processam pagamentos via Braintree, uma empresa do PayPal. Os comerciantes que utilizam a Braintree, plataforma de pagamento do $m$-commerce (comércio móvel), poderão integrar facilmente o Masterpass em suas experiências de checkout, "proporcionando uma experiência de usuário ininterrupta para os consumidores." 
- Parcerias com bancos: Em 2019, o Itaú e o PayPal firmaram um acordo para que todos os clientes que possuem cartão de crédito emitido pelo Itaú Unibanco possam vinculá-lo à PayPal a partir dos aplicativos do banco. O usuário abre uma conta no PayPal e cadastra seus cartões de crédito. Depois que os cartões são validados, é possível usar o PayPal para fazer pagamentos — os valores serão cobrados pelo serviço nas faturas dos cartões. Com a parceria, o cadastro no PayPal fica mais fácil, pois os clientes do Itaucard, por exemplo, podem se cadastrar no PayPal a partir do aplicativo do cartão, e, para quem já têm conta, é possível vincular o cartão de crédito ao PayPal por ali rapidamente.

- Novos negócios: Visando expandir seu alcance global, ampliar a rede de usuários e agregar novos serviços financeiros, o PayPal adquire outras startups que estão presentes em locais estratégicos para o negócio e que oferecem serviços inovadores, desenvolvidos por meio de tecnologia moderna. As empresas adquiridas, são consideradas como unidades de negócios, mantém sua estrutura e processos funcionamento normalmente, de forma que as startups não percam sua essência. Segundo CFO, “ $a$ Xoom é um membro da familia PayPal, realiza parcerias com empresas comprovadas em todo o mundo para prover transferências de modo conveniente, seguro e barato, utilizando conta bancária, cartão de débito ou crédito". Para a realização das transações, é utilizado o conceito de pagamentos person-to-person (P2P), também denominado pessoa para pessoa, é uma tecnologia online que permite aos clientes transferir fundos de sua conta bancária ou cartão de crédito para a conta de outro indivíduo pela Internet ou por um telefone celular. Em março de 2018, o PayPal adquiriu a startup europeia de tecnologia financeira iZettle por US $\$ 2,2$ bilhões. A iZettle produz máquinas de cartões que permite que pequenas empresas recebam pagamentos com cartões a preços acessíveis. O acordo também significa que o PayPal ganha presença em 11 novos mercados: Brasil, Dinamarca, Finlândia, França, Alemanha, Itália, México, Holanda, Noruega, Espanha e Suécia. A Braintree é um parceiro de pagamentos completo, auxilia empresas de todo porte a processar pagamentos para ajudar a maximizar as oportunidades de negócios e o crescimento da receita.

\section{BMC - Criação de Valor - Atividades-Chave}

O PayPal visa aumentar a relevância da empresa para consumidores e comerciantes, permitindo o acesso online e a movimentação do dinheiro em qualquer lugar do mundo, a qualquer momento, em qualquer plataforma e por meio de qualquer dispositivo. Oferece formas seguras e simples para empresas de todos os tamanhos aceitarem pagamentos de sites comerciais, dispositivos móveis e aplicativos, e em locais de varejo offline, por meio de uma ampla gama de soluções de pagamento na plataforma de pagamentos. Opera uma plataforma de pagamentos aberta e segura, que demonstra ser funcional, independente da tecnologia que as empresas utilizam para fazer transações com seus clientes, sejam elas online, nas lojas ou em dispositivos móveis. Em 2015, 28\% dos 4,9 bilhões de pagamentos processados foram feitos através de dispositivos móveis. As atividades-chave seguem relacionadas na Figura 8. 
Para os clientes realizarem compras, é necessário cadastrar uma conta grátis no site da empresa, ter um cartão de crédito, CPF (Cadastro de Pessoa Física) e CEP (Código de Endereçamento Postal), onde todos os dados do cartão são criptografados e caso seja identificada alguma não conformidade com a política da empresa, o cadastro é bloqueado. Como serviços diferenciados, oferece proteção na realização das compras online, e se o produto não chegar ou for diferente do que foi comprado através do site, o cliente tem até 180 dias de proteção para receber a devolução do pagamento. Caso o produto comprado chegar, mas não agradar o cliente, a empresa ajuda o cliente na resolução e recebem o frete grátis na devolução.

Realização de doações

O PayPal incentiva as pessoas a doarem a diferentes organizações beneficentes e sem fins lucrativos. Através deste serviço, é possível incentivar as pessoas a doarem com uma experiência rápida $e$

descomplicada. $O$ doador pode escolher no site a sua causa, clicar no botão "Doe com o Caso X", escolher doar uma vez ou configurar doações recorrentes, recebendo em seguida a confirmação da doação.

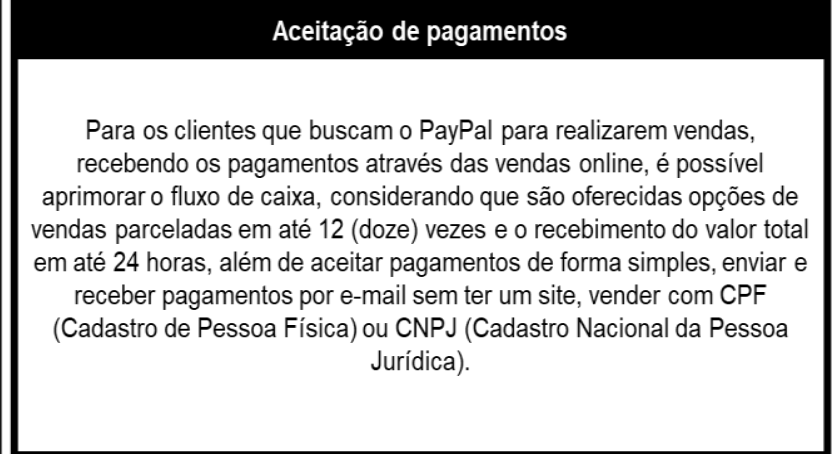

Envio de pagamentos no Brasil e para o exterior

Nessa modalidade o usuário pode fazer compras em lojas de comércio eletrônico e utilizar a sua própria conta para realizar o pagamento. Aos clientes que querem enviar pagamentos no Brasil e para o exterior, é possível enviá-los para qualquer e-mail válido e os dados financeiros do cliente ficam protegidos pelo PayPal, sendo que o destinatário não possui acesso aos detalhes da conta bancária ou numeração do cartão. Para que o cliente utilize esse serviço, basta ter um número de telefone ou endereço de e-mail. $O$ cliente pode usar o saldo da conta no PayPal, a partir de débito em conta, ou cartão de crédito, e o pagamento é enviado à conta do PayPal do destinatário.

Figura 8: Atividades-chave do PayPal.

Fonte: Elaborado pelos Autores.

\section{BMC - Criação de Valor - Recursos-Chave}

- Plataforma multimoeda: O PayPal é uma plataforma de pagamentos global que está disponível para pessoas em mais de 200 mercados, permitindo que os clientes sejam pagos em mais de 100 moedas, retirem fundos para suas contas bancárias em 56 moedas e mantenham saldos nas contas do PayPal em 25 moedas. Desse modo, não é necessário informar o cartão de crédito à loja e a informação fica restrita à PayPal, que faz a intermediação de toda a operação, repassando os valores para a empresa e, quando cabível, protegendo o usuário de eventuais fraudes. No Brasil, o PayPal oferece as quatro grandes soluções aos clientes.

- Tecnologia: A área de tecnologia da informação responsável pelo desenvolvimento, está posicionada hierarquicamente abaixo do COO (Chief Operating Officer, também denominado diretor de operações). Segundo o CFO, esta área é o "coração da empresa”, possui o maior número de profissionais considerando que a tecnologia é o principal diferencial da empresa. O PayPal apresenta recursos tecnológicos de ponta, como inteligência artificial e sistemas de criptografia. A inovação tecnológica é verificada por meio dos vários recursos como Smart Incentives, que tem a capacidade de interagir diretamente com os mais de 200 milhões de clientes do PayPal no início de sua jornada de compras; ao permitir que os comerciantes exibam mensagens promocionais do PayPal em torno de recursos como o PayPal Credit e One Touch em suas páginas iniciais e de produto, os comerciantes com lojas online habilitadas podem adicionar o aplicativo PayPal Marketing Solutions para ativar automaticamente os banners do PayPal Credit em páginas estratégicas em toda a sua experiência de compra. O PayPal Marketing Solutions, lançado em 2017, oferece novas ferramentas de marketing e análise que ajudam as empresas a entender melhor seus clientes e criar experiências de compras envolventes que ajudam a aumentar as vendas. O produto One Touch permite que o cliente após realizar a primeira transação com o One Touch ativado, o dispositivo permanece conectado ao PayPal por 6 meses, permitindo ao cliente não precisar inserir novamente a sua senha ou dados de acesso. O recurso Shopper Insights inclui informações agregadas e anônimas sobre os comportamentos e preferências dos compradores do PayPal no site de um comerciante. 
- Segurança: O PayPal traz segurança para os pagamentos porque os números do cartão de crédito não são compartilhados. O cliente digita os números do cartão apenas uma vez, no momento da criação da conta, e nas próximas compras, é necessário informar apenas o e-mail e a senha cadastrados para realizar o pagamento. Neste sentido, os principais diferenciais oferecidos pelo PayPal "são a segurança, velocidade e praticidade". A empresa possui uma equipe de fraude global, monitorando as transações realizadas com o PayPal em tempo real, 24 horas por dia, devido ao alto índice de tentativas de fraudes. Todos os pagamentos e dados dos clientes ficam protegidos por um dos mais modernos e rigorosos sistemas de criptografia de dados do mercado. O PayPal conquistou a certificação PCI DSS (Padrão de Segurança de Dados da Indústria de Cartões de Pagamento), atribuída às empresas que seguem as melhores práticas do mercado em segurança de dados financeiros.

- Logística Reversa: Segundo o CFO, "um dos diferenciais oferecidos pelo PayPal é o programa de proteção ao comprador e ao vendedor". Se o produto chegar, mas não agradar o cliente, o PayPal tem frete grátis na devolução, além de proteger o cliente contra pagamentos não autorizados enviados da conta do PayPal. Caso o produto não seja enviado, o cliente recebe o dinheiro de volta e não paga nada a mais por isso. Há também reembolso para produtos errados, se um produto não chegar ou não for igual à descrição do vendedor, o cliente pode receber o pagamento de volta integralmente. A Proteção ao Vendedor do PayPal ajuda a proteger os vendedores caso um comprador registre uma reclamação de que o pagamento não foi autorizado, ou caso um comprador registre um chargeback junto ao emissor do cartão alegando que não recebeu o produto. Segundo o CFO, a "Proteção ao Vendedor será ampliada para produtos intangiveis, como viagens, serviços de tíquetes e produtos digitais".

\section{BMC - Entrega de Valor -Segmentos de Mercado}

Através de um efeito acumulativo de muitas ações tomadas pelo PayPal, a empresa tem impulsionado a aceleração no crescimento de novas contas de usuários e o envolvimento do cliente com os principais serviços do PayPal. Este processo de ampliação da base de clientes, é realizado através da base de clientes ativos, realização de campanhas de descontos aos clientes e agregação de clientes através dos parceiros. Em 2018, a empresa possuía aproximadamente 237 milhões de contas ativas, sendo 218 milhões de contas como PF (Pessoa Física) e 19 milhões de PJ (Pessoa Jurídica) no mundo e, no Brasil, cerca de 4 milhões de usuários no país (2019).

\section{BMC - Entrega de Valor - Canais do Cliente}

Os canais do cliente estão representados por qualquer plataforma e por meio de qualquer dispositivo. As transações podem ser realizadas por meio de sites comerciais, dispositivos móveis e aplicativos, e em locais de varejo offline, por meio de uma ampla gama de soluções de pagamento na plataforma de pagamentos. $\mathrm{Na}$ interação com os clientes, o canal é totalmente na forma online, pois não possui estabelecimentos físicos para atender seus clientes.

\section{BMC - Entrega de Valor - Relação com o Cliente}

O PayPal possui uma estrutura de call center diferenciada, com aproximadamente 70 atendentes com alto nível de qualificação técnica e conhecimento em idiomas. As principais responsabilidades do profissional da área de Customer Solutions, é ajudar os clientes a resolver suas dúvidas, utilizando as mais recentes ferramentas de comunicação e tecnologia. As soluções de marketing do PayPal foram projetadas para ajudar as empresas a aumentar as vendas por meio de uma maior visibilidade de seus possíveis clientes e clientes em várias plataformas, dispositivos e sistemas operacionais.

Segundo o CFO, "clientes de dois lados da plataforma necessitam visualizar novos valores adicionados e para entender como e porque usar pagamentos móveis em comparação com esquemas de cartão padronizados é benéfico para eles." O atendimento é de forma personalizada, procura analisar métricas (tempo de atendimento por telefone, experiência do cliente, análise de oportunidades e dos perfis e comportamentos de cada cliente, através 
de base de dados, inteligência artificial, realização de campanhas através de sites). Analisa os dados em duas principais frentes, sendo o mercado e o consumidor, desta forma, há uma equipe dedicada e focada para realização de cada tipo de análise. As análises realizadas acontecem através de dados do passado, presente e projeções de futuro, cada operação e transação é analisada detalhadamente, considerando os parceiros de negócios, clientes, diversos períodos (anual, mensal, diário), análises por parcela e por transação.

\section{BMC - Captura de Valor}

- Receita: A compra é gratuita para compras feitas no Brasil. As tarifas para vender e receber pagamentos pela conta do PayPal incluem tarifas aplicáveis em situações de um pagamento pela venda de mercadorias ou serviços, quando da solicitação de pagamentos de um comprador no website do PayPal ou um pagamento para bens e serviços que é enviado para, ou recebido por, uma empresa ou pagamentos recebidos por uma entidade sem fins lucrativos. Se os pagamentos recebidos são provenientes de uma conta PayPal, o cliente paga um valor mais baixo por transação no Brasil, do que fora do Brasil.

Há também a tarifa de processamento de pagamentos parcelados, ou seja, se o usuário pagador (duas a doze parcelas) decidir efetuar um pagamento em parcelas por meio do website do PayPal, a tarifa do usuário recebedor se baseará no número de parcelas que o usuário pagador selecionar. O PayPal oferece dois programas de tarifas de micropagamentos e quanto à pagamentos em lote, dentro e fora do Brasil, $2 \%$ do pagamento, até a tarifa máxima de pagamentos em lote por destinatário abaixo relacionada. A tarifa de Chargeback é cobrada na conta quando um pagamento recebido é sujeito a Chargeback. Se o cliente estiver qualificado para a proteção ao vendedor do PayPal nesse pagamento, a tarifa não será cobrada. Há uma política para o comerciante de permitir tarifas mais baixas.

- Custos: Estão estruturados em torno da folha de pagamento, infraestrutura tecnológica e despesas de marketing.

\section{BMC - Proposta de valor}

\begin{tabular}{|c|c|}
\hline $\begin{array}{l}\text { Cartão Pré-Pago Digital } \\
\text { PayPal }\end{array}$ & $\begin{array}{l}\text { A partir de 2019, o PayPal foi autorizado a lançar cartões pré-pagos no Brasil, o Banco } \\
\text { Central liberou a empresa para atuar como instituição de pagamento na modalidade } \\
\text { "emissor de moeda eletrônica". Isso significa que ela poderá gerenciar contas de } \\
\text { pagamento do tipo pré-paga, com recursos depositados previamente. Oferece aos } \\
\text { clientes a possibilidade de realizar compras internacionais, sem a necessidade de ter } \\
\text { um cartão de crédito com uma instituição bancária. Os benefícios para comprar com } \\
\text { o cartão pré-pago são isenção da anuidade, pagamento com cartão de crédito ou boleto } \\
\text { bancário, sem alteração da variação cambial, aceitos em sites internacionais. Não há } \\
\text { variação do câmbio, pois o cliente deve escolher o valor, fazer a recarga e confirmar o } \\
\text { pedido. "A operação de câmbio é fechada na hora da compra, de forma transparente, sem taxas } \\
\text { extras ou anuidade." }\end{array}$ \\
\hline încis do & $\begin{array}{l}\text { Segundo o CFO, "o cliente é colocado no centro do negócio". A experiência do cliente é } \\
\text { aperfeiçoada pois recorre-se à expertise do e-commerce para melhorar a vida } \\
\text { financeira dos clientes em geral. Cada solicitação de atendimento é lançada em uma } \\
\text { base de dados, e periodicamente o PayPal faz uma análise dos motivos e seus } \\
\text { respectivos planos de ação para solução de cada situação apresentada pelos clientes. } \\
\text { O segmento de clientes, apresentam dois pares distintos (B2B e B2C), pois para cada } \\
\text { grupo de clientes (ou lado), há a proposta do valor, a qual supre as necessidades de } \\
\text { cada um dos grupos de clientes interdependentes, pois não é possível entregar uma } \\
\text { proposta de valor sem a outra. }\end{array}$ \\
\hline Inovação Tecnológica & $\begin{array}{l}\text { A inovação contínua é focada na criação de ferramentas de pagamento e comércio que } \\
\text { conectam comerciantes e consumidores de maneiras exclusivas que só são ativadas } \\
\text { pela two-sided network. Por meio destas ferramentas, os consumidores e os comerciantes } \\
\text { conectam-se em novos contextos e procuram comprar facilmente as coisas que } \\
\text { desejam e precisam, ao mesmo tempo em que ajudam as empresas a crescer em um } \\
\text { cenário de varejo cada vez mais competitivo. O PayPal analisa os perfis e } \\
\text { comportamentos de cada cliente, através de base de dados, por meio de inteligência }\end{array}$ \\
\hline
\end{tabular}




\begin{tabular}{|l|l|}
\hline & $\begin{array}{l}\text { artificial, realização de campanhas através de sites, facilidade na criação das contas, } \\
\text { tornando a experiência rápida e segura. }\end{array}$ \\
\hline $\begin{array}{l}\text { Democratização do } \\
\text { dinheiro }\end{array}$ & $\begin{array}{l}\text { O PayPal continuará trabalhando na estruturação de um ecossistema para inclusão } \\
\text { financeira, permitindo que as pessoas tenham inclusão digital. Será necessário abrir } \\
\text { frentes de trabalho em regiões que ainda não possuem um alto nível de maturidade no } \\
\text { e-commerce, pois há mercados com grande potencial, mas que ainda não estão tão } \\
\text { habilitados com o e-commerce. }\end{array}$ \\
\hline
\end{tabular}

Figura 9: Proposta de valor do negócio da Paypal segundo BMC

Fonte: Elaborado pelos autores.

\section{Análise do caso a partir do modelo de pesquisa}

O modelo BMC-Canvas proposto por Osterwalder \& Pigneur (2011) deixa implícito que a partir da reflexão do desenvolvimento do modelo de negócio é necessário pensar de forma estratégica. Sua aplicabilidade no Paypal (figura 10) expõe diferentes possibilidades de reflexões e discussões na organização de todos os pontos nevrálgicos e permite que se faça uma análise da criação, da distribuição e da proposta de valor mediante a experiência de aprendizado visual do seu negócio.

O Paypal é enquadrado como uma "fintech sustentável", definida como provedor de serviços financeiros estabelecido que trabalha para proteger suas posições de mercado fazendo uso de TI por meio de inovações incrementais. O PayPal, é focado na criação de ferramentas de pagamento e comércio que conectam comerciantes e consumidores de maneiras exclusivas que só são ativadas pela rede de dois lados (two-sided network). Isso é extremamente importante, já que os consumidores (B2B) e os comerciantes (B2C) se conectam em novos contextos e procuram comprar facilmente as coisas que desejam e precisam, ao mesmo tempo em que ajudam as empresas a crescer em um cenário de varejo cada vez mais competitivo.

A importância destes efeitos para o crescimento da rede é tamanha que as plataformas de negócios muitas vezes injetam recursos para atrair participantes de um dos lados do mercado. Eles sabem que, se conseguirem a forte adesão de um lado, o outro acompanhará o movimento. Desta forma, o crescimento do PayPal alimenta um poderoso efeito de rede (network effect) positivo para a empresa e este tipo de crescimento se impulsiona. Quanto mais usuários se inscrevem na plataforma, mais importante o serviço se torna para os varejistas adotarem, e quanto mais lugares aceitarem, mais atraentes serão os novos usuários. Um exemplo são as soluções de pagamento person-to-person, pessoa a pessoa, ("P2P") por meio dos produtos PayPal e Xoom que impulsionam o volume P2P total, permitindo transferências P2P nacionais e internacionais na plataforma de pagamentos. 


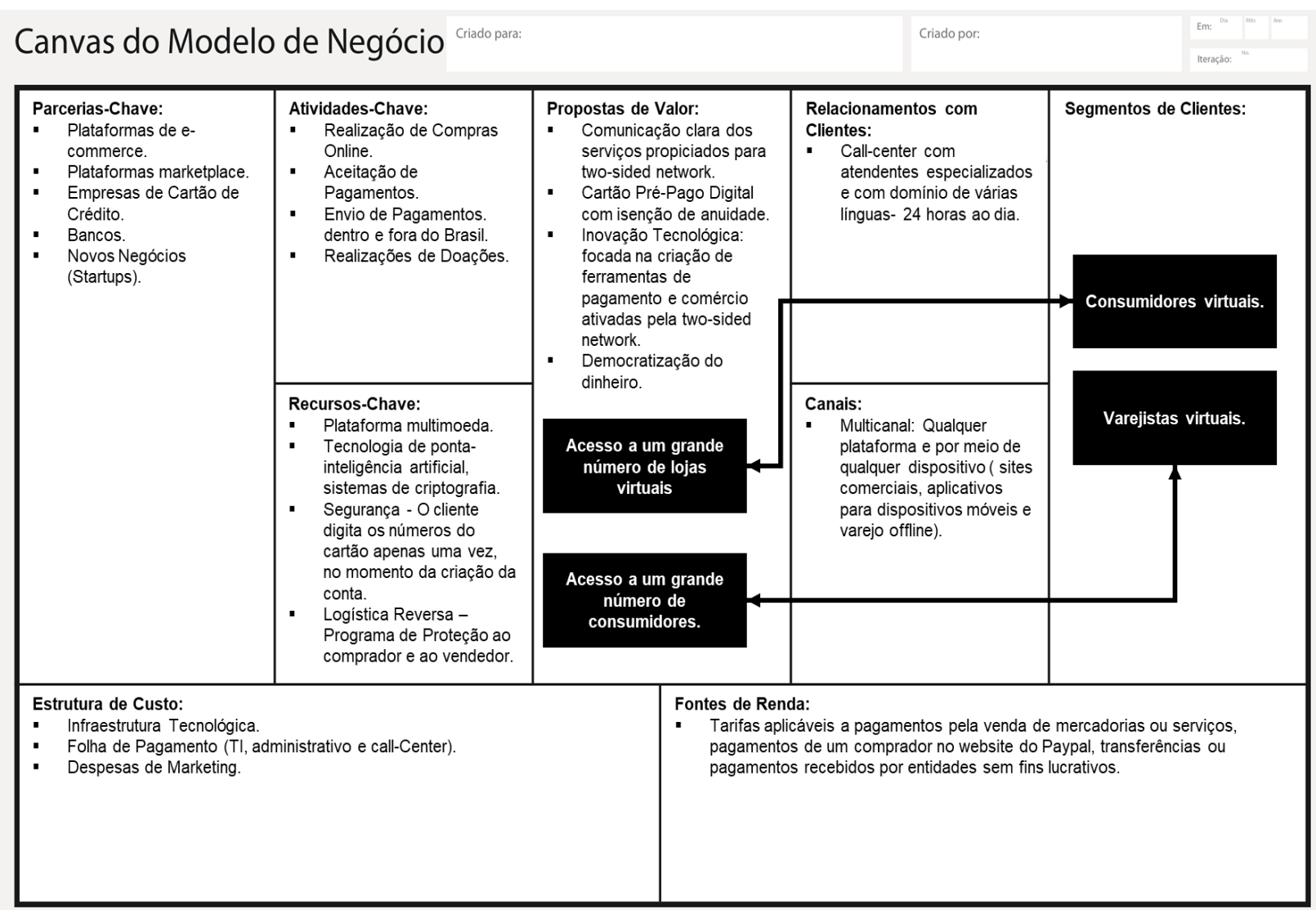

Figura 10 Modelo BMC Paypal

Fonte: Elaborado pelos autores.

Outro bom exemplo é a parceria com o banco Itaú, a qual prevê este efeito, pois ajudará o PayPal a ampliar a sua base de clientes no Brasil, pelo fato do banco atualmente controlar quase 34 milhões de cartões de crédito, e o acordo deve permitir que o uso de seus serviços de pagamento aumente no comércio eletrônico. A parceria realizada com Mercado Livre possibilitará oferecer como método de pagamento pelos comerciantes que usam o PayPal em todo o mundo, cerca de 300 milhões de clientes do PayPal, os serviços do Mercado Pago, a fintech financeira de 48 milhões de usuários no Brasil e no México, nas compras online. Em contrapartida, o Paypal também será aceito no marketplace do Mercado Livre para compras internacionais. Essas parcerias não apenas direcionam novos membros para a plataforma, mas aumentam o engajamento entre os diferentes clientes.

A partir do estudo de caso do PayPal percebe-se que os atributos de criação de valor de uma plataforma de pagamentos podem ser alcançados por meio do lock-in e pelo caráter inovador, conduzindo a uma proposta de valor onde o caráter inovador tem a vantagem em atrair e reter clientes, especialmente em conjunção com uma marca forte. A proposta de valor (Figura 9) destaca o processo e a estratégia do modelo de negócios do Paypal que tem como recurso-chave as inovações tecnológicas propiciadas pelo analytics, que permite conhecer o comportamento do consumidor e a inteligência artificial por meio do machine learning em que as ferramentas de marketing são baseadas e que impulsionam o efeito de rede, na realização de compras recorrentes.

A análise do caso sugere que a plataforma de e-business reforça o lock-in por habilitar clientes em customizar produtos, serviços ou informação para as suas necessidades individuais em uma variedade de maneiras. Este argumento ganha força quando as oportunidades para a customização (iniciada pelo cliente) e a personalização (iniciada pelo e-business) são exploradas, por meio do PayPal Marketing Solutions, Shopper Insights, Paypal Credit e conduzindo os 203 milhões de contas de consumidor ativas, 16 milhões de comerciantes na plataforma do One Touch. 
A comunicação clara dos serviços propiciados para two-sided network pelo PayPal é realçada quando se estabelece e se mantém bons relacionamentos com ambos os segmentos de clientes, sendo este um fator importante no sucesso de uma empresa organizada como plataforma de dois lados. A eficiência nos negócios online do Paypal é percebida quando oferece uma maneira simples e segura de pagar as compras na internet, no celular, no tablet ou onde o cliente estiver, por transações multimoeda permitindo uma abordagem fácil e conveniente. Da mesma forma, a comunicação apropriada de valor proposta e incentivos para o varejista são verificados, ao propiciar novas formas de pagamentos e viabilizando o suporte para as respectivas operações. Com o PayPal, os dados financeiros, como números de cartão de crédito e de conta bancária, não são compartilhados com os vendedores, pois a segurança é considerada um ponto nevrálgico na adesão da plataforma.

O caráter inovador é conectado com a complementaridade, com o intuito de combinar recursos e capacidades de diferentes maneiras, que permite agregar valor viabilizando acréscimos de receita, como por exemplo, ativos offline que complementam ofertas online. Ao adquirir ou realizar parcerias com startups, o PayPal cria um ambiente que fomenta a criatividade e incentiva a produtividade. É verificada por meio da combinação com empresas como a iZette que produz máquinas de cartões e que implica oferecer soluções multicanal (omnichannel) para os varejistas. Também é percebida nos programas de proteção ao comprador e ao vendedor que aprimoram a experiência do cliente e consequentemente favorece o aumento de receita do PayPal, com as despesas previstas no orçamento da área de marketing, não trazendo impactos ao fluxo de caixa da empresa.

À medida que as compras acontecem cada vez mais em plataformas alternativas, os varejistas tradicionais buscam estar aptos a receber pagamentos por meio de diferentes canais: online, loja física e celular. Ao combinar as máquinas da iZettle com o know-how online do PayPal, o grupo pode se lançar como a única solução para os comerciantes que procuram resolver todos os seus problemas de pagamento.

Percebe-se que uma das premissas básicas das fintechs podem ser visualizadas na proposta de valor (Figura 9) do PayPal relativa à "democratização" do dinheiro, pois a empresa acredita na inclusão financeira e digital por meio da distribuição ampla e global, permitindo o incremento do acesso por mais pessoas e empresas. A empresa acredita que é possível usar a expertise do e-commerce para melhorar a vida financeira dos clientes e promover a inclusão digital. Procuram comprovar por meio da utilização do cartão prépago Paypal na compra de produtos com acesso a milhões de sites internacionais, com o benefício da isenção da anuidade, possibilitando que os consumidores efetivem seus pagamentos sob diferentes cenários sem alteração da variação cambial.

Por fim, conforme Parker et al. (2016), a adesão descomplicada é a possibilidade de se ligar a uma plataforma com rapidez e facilidade, começando logo a participar da criação de valor viabilizada por ela. Isto é constatado no PayPal pela facilidade de cadastramento propiciada aos usuários, bem como na transferência, a utilização de uma única conta sem utilização de outros cartões, bastando um número de telefone ou endereço de e-mail que permitem à plataforma crescer organicamente quase sem limites.

O desafio constante do Paypal, como uma plataforma two-sided network, é o crescimento em escala de uma rede que exige que ambos os lados do mercado aumentem proporcionalmente. Administrar o ecossistema de fintechs e parceiros com vistas a facilitar transações entre os distintos tipos de usuários de plataformas, criar uma massa crítica e assim desencadear os efeitos potenciais de rede, permite criar e capturar valor para todos, evitando o efeito de rede negativo que acontece no crescimento em quantidade, que impossibilita o melhor pareamento entre produtores e consumidores.

\section{Considerações finais}

O objetivo deste estudo foi analisar a abordagem do modelo de negócios, com relação à sua proposta de valor, de uma plataforma provedora de pagamentos móveis frente aos desafios que encontra para obter o engajamento de uma massa crítica de usuários nos mercados B2B e B2C. Para o alcance deste objetivo 
foi utilizado o modelo estratégico Business Model Canvas (BMC), o qual por meio de seus elementos, permite conhecer como um modelo de negócios de caráter inovador fornece oportunidades sólidas para a criação e captura de valor por parte de uma fintech.

Com este intuito, foi possível evidenciar a proposta de valor da fintech líder na categoria de pagamentos digitais, calcada na comunicação clara para a rede de dois lados (two sided network), a qual no caso estudado, o efeito de rede é salientado por meio da criação de valor propiciada pelas parcerias-chave que auxiliam o crescimento exponencial, mantendo-se à frente de seus competidores. E isto só é possível pela inovação tecnológica focada na criação de ferramentas de pagamento e comércio que conectam comerciantes e consumidores de maneiras exclusivas reforçando continuamente a two-sided network, fazendo com que quanto mais usuários se inscrevem na plataforma, mais importante o serviço se torna para os varejistas adotarem, e quanto mais aceitarem, mais atraentes serão para os novos usuários.

Portanto, este estudo serve como contribuição para a estratégia das fintechs de pagamentos móveis que pretendem obter sucesso em virtude da digitalização dos negócios e pela adoção de métodos eletrônicos de pagamentos impulsionadas pela crise da pandemia do COVID-19. Paralelamente, as fintechs podem vir a ser a solução para as "desbancarizados", bem como para os pequenos e médios negócios, por facilitar o acesso a recursos, pela democratização proporcionada, ao contrário das instituições financeiras tradicionais, que historicamente os excluem.

O estudo apresenta como limitação a aplicação do BMC com o não envolvimento de grupos e parceiros existentes, bem como funcionários da empresa, pois foi um exercício realizado pelos autores mediante as informações levantadas no estudo de caso. Outra limitação é a de que há um entendimento na literatura de que um estudo de caso único não pode fornecer informações confiáveis para generalização dos achados. Porém, como salientado anteriormente ao mencionar a singularidade do caso, o Paypal é considerado um paradigma no estudo de fintechs de plataformas móveis, por apresentar a vantagem do first mover com o seu modelo de negócios de valor de sucesso calcado na dinâmica de feedback positivo que deriva de externalidades de rede. Para pesquisas futuras, sugere-se a continuidade na análise de outros modelos de negócios de fintechs brasileiras, principalmente as que possibilitam acesso ao crédito.

\section{Referências}

Abraham, S., (2013). Will business model innovation replace strategic analysis? Strategy \& Leadership, 41 (2), 31-38. Amit, R \& Schoemaker P. (1993). Strategic assets and organizational rent. Strategic Management Journal,14(1), 33-46. Amit, R.\& Zott, C., (2001), Value Creation in E-business. Strategic Management Journal, 22, 493-520.

Apanasevic, T., Markendahl, J. \& Arvidsson, N., (2016). Stakeholders' expectations of mobile payment in retail: lessons from Sweden. International Journal of Bank Marketing, 34(1),2016, 37-61.

Banco Central do Brasil - Bacen (2020). Fintechs. Recuperado em 28 de maio, 2020 de https://www.bcb.gov.br/estabilidadefinanceira/fintechs

Bardin, L. (2006). Análise de conteúdo. Lisboa: Edições 70.

Bettinger, A., (1972). FINTECH: A series of 40 time shared models used at manufacturers hanover trust company. Interfaces, 62-63.

Bocken, N.M.P., Short, S.W., Rana, P. \& Evans, S., (2014). A literature and practice review to develop sustainable business model archetypes. Journal of Cleaner Production, 65, 42-56.

Chan, S. P. (2020, março). Coronavírus: Economia global vai sofrer anos até se recuperar do impacto da pandemia, afirma OCDE. bbc.com, Recuperado em 10 de maio, 2020, de https://www.bbc.com/portuguese/internacional$\underline{52002332}$

Chesbrough, H.W., (2006). Open business models: how to thrive in the new innovationlandscape. Research Management, 50, 256.

Chesbrough, H. (2010). Business model innovation: Opportunities and barriers. Long Range Planning, 43(2-3). 354363. 
Chiu, I.H.-Y., (2016). FinTech and disruptive business models in financial products, intermediation and markets Policy implications for financial regulators. Journal of Technology Law \& Policy 21, 55-112.

Casadesus-Masanell, R. \& Ricart, J. E. (2010). From Strategy to Business Models and onto Tactics. Long Range Planning, 43, 195-215.

Christensen, C.M., (2003). The innovator's dilemma: The revolutionary book that will changed the way you do business. Boston: Harvard Business Review Press.

Dahlberg, T., Guo, J. \& Ondrus, J., 2015. A critical review of mobile payment research. Electronic Commerce Research and Applications, 14 (5), 265-284.

Dorf, Bob \& Blank, Steve (2012). The Startup Owner's Manual - the Step-by-Step Guide for Building a Great Company. California: K \&S Ranch Publishers.

Dyer, W. G.; Wilkins, A. L. \& Eisenhardt, K.M. (1991) Better Stories, Not Better Constructs, to Generate Better Theory: A Rejoinder to Eisenhardt. The Academy of Management Review, 16 (3) p. 613.

E-investidor (2020, out). Como a explosão digital na pandemia revoluciona o setor financeiro no mundo todo. Recuperado em 1 de dezembro, 2020, de https://einvestidor.estadao.com.br/comportamento/explosao-digital$\underline{\text { setor-financeiro }}$

Eisenmann, T., Parker, G., Van Alstyne \& Marshall, W. (2006, october). Strategies for Two-Side Markets. Harvard Business Review.

Fintechlab, (2020, abril) Fintechs estão autorizadas a fazer o pagamento dos R\$ 600 do "coronavoucher". Recuperado em 10 de maio, 2020, de https://fintechlab.com.br/index.php/2020/04/03/fintechs- estaoautorizadas-a-fazer-o- pagamento-dos-r-600-docoronavouche/

Fortnum, D., Pollari, I., Mead, W., Hughes, B. \& Speier, A., (2017). The pulse of fintech Q12017: Global analysis of investment in fintech. KPMG technical report, NewYork. Recuperado em 15 de maio, de https://assets.kpmg.com/content/dam/kpmg/xx/pdf/2017/04/pulse-of-fintech-q1.pdf

Furlan, F. (2019, dezembro). PayPal e Mercado Livre ampliam uso de carteiras digitais para 350 milhões de usuários. Valor.globo.com. Recuperado em 15 de maio, 2020 de https://valor.globo.com/financas/noticia/2019/12/30/paypal-e-mercado-livre-ampliam-uso-de-carteirasdigitais-para-350-milhes-de-usurios.ghtml

Gabor, D. \& Brooks, S., (2017). The digital revolution in financial inclusion: international development in the fintech era. New Political Economy, 22, 423-436. Recuperado em 28 de maio, 2020, de https://doi.org/10.1080/13563467.2017.1259298

Gil, A. C. (2009). Estudo de Caso. São Paulo: Editora Atlas.

Global State Of Fintech: Investment \& Sector Trends To Watch. (2019).Recuperado em 28 de maio, 2020 de https://www.cbinsights.com/reports/CB-Insights Fintech-Report-Q4-2019.pdf

Godoi, C. K., Bandeira-De-Melo, R., \& Silva, A. B. (Orgs.). (2010). Pesquisa qualitativa em estudos organizacionais: paradigmas, estratégias e métodos. (2a ed.) São Paulo:Saraiva, p, 304.

Gomber, P., Koch, J.-A. \& Siering, M., (2017). Digital Finance and FinTech: Current research and future research directions. Journal of Business Economics, 87, 537-580. Recuperado em 29 de maio, 2020 de https://doi.org/10.1007/s11573-017-0852-x

Gomber, P, Kauffman, R. J., Parker,C. \& Weber, B.W. (2018) On the Fintech Revolution: Interpreting the Forces of Innovation, Disruption, and Transformation in Financial Services. Journal of Management Information Systems, 35(1), 220-265, Recuperado em 29 de maio, 2020, de https://doi.org/10.1080/07421222.2018.1440766

Gulati R. (1999). Network location and learning: the influence of network resources and firm capabilities on alliance formation. Strategic Management Journal, 20 (5), 397-420.

Hagiu, A. \& Wright, J., (2015). Multi-sided platforms. International Journal of Industrial Organization, 43, 162-174.

Hagiu A. \& Rothman, S. (2016). Network effects aren’t enough. Harvard Business Review, April.

Ikävalko, H., Turkama, P. \& Smedlund, A. (2018). Value creation in the internet of things: mapping business models and ecosystem roles, Technology Innovation Management Review, 8 (3), 5-15.

Iman, N., (2018). Is mobile payment still relevant in the fintech era? Electronic Commerce Research and Applications, 30, $72-82$. 
Informoney (2019, agosto). Brasil tem 45 milhões de desbancarizados, diz pesquisa Recuperado em 29 de maio, 2020 de https://www.infomoney.com.br/minhas-financas/brasil-tem-45-milhoes-de-desbancarizados-dizpesquisa

Jocevski, M., Ghezzib, A. \& Arvidsson,N.(2020). Exploring the growth challenge of mobile payment platforms: A business model perspective. Electronic Commerce Research and Applications, 40.

Kaplan, S., (2012). The Business Model Innovation Factory: How to Stay Relevant When the World Is Changing. Wiley. com.

Katz M.L. \& Shapiro C. (1985). Network externalities, competition, and compatibility. American Economic Review, $75,424-440$.

Kauffman, R.J. \& Ma, D., (2015). Special issue: contemporary research on payments and cards in the global fintech revolution. Electronic Commerce Research and Applications. 14, 261-264.

Kazan, E. \& Damsgaard, J. (2013). A framework for analyzing digital payment as a multi-sided platform: a study of three European NFC solutions. In: Proceedings of the European Conference on Information Systems, Association for Information Systems, Atlanta, GA.

Langley, A. (1999). Strategies for Theorizing from Process Data.The Academy of Management Review, 24 (4), 691 -711. Laya, A., Markendahl, J. \& Lundberg, S., (2018). Network-centric business models for health, social care and wellbeing solutions in the internet of things, Scandinavian Journal of Management,34, 103-11.

Loebbecke, C. \& Picot, A. (2015), "Reflections on societal and business model transformation arising from digitization and big data analytics: a research agenda", The Journal of Strategic Information Systems, 24(3), 149-157.

Mallat, N, (2007), Exploring consumer adoption of mobile payments - A qualitative study, The Journal of Strategic Information Systems, 16 (4), 413-432.

Massa, L. \& Tucci, C. L. (2014). Business model innovation. In M. Dodgson, D. M. Gann, \& N. Phillips (Eds.), The Oxford Handbook of Innovation Management (pp. 420-441). Oxford, UK: Oxford University Press.

Menke, L. \& de Lussanet, M., (2006). SMS-Based Mobile Payment: Popular with the Young. Forrester Research.

Milian, E. Z., Spinola, M. \& Carvalho, M. M. (2019). Fintechs: A literature review and research agenda, Electronic Commerce Research and Applications, 34.

Muzellec, L, Ronteau, S \& Lambkin, M, (2015). Two-sided Internet platforms: A business model lifecycle perspective, Industrial Marketing Management, 45,139-150.

Nielsen, C \& Lund, M. (2015). The Concept of Business Model Scalability. SSRN, march, 9

Nordic Innovation, (2012). Green Business Model Innovation: Conceptualisation Next Practice and Policy. Nordic Innovation.

Ondrus, J., Pigneur, Y., (2006). Towards a holistic analysis of mobile payments: a multiple perspectives approach. Electronic Commerce Research and Applications, 5 (3), 246-257.

Ondrus, J., Gannamaneni, A. \& Lyytinen, K., 2015. The impact of openness on the Market potential of multisided platforms: a case study of mobile payment platforms. Journal of Information Technology. 30, 260-275. Recuperado em 20 de maio, 2020, de https://doi.org/10.1057/jit.2015.7

Orofino, M. A. Rodrigues. (2011). Técnicas de criação de conhecimento no desenvolvimento de Modelo de Negócios. Florianópolis: UFSC.

Osterwalder, A. \& Pigneur, Y., (2011). Business Model Generation: Inovação Em Modelos De Negócios. São Paulo: Alta Books Editora.

Palo, T.\& Tähtinen, J. (2011). A network perspective on business models for emerging technology-based services, Journal of Business \& Industrial Marketing, 26 (5), 377-388.

Palo, T. \& Tähtinen, J. (2013). Networked business model development for emerging technology-based services, Industrial Marketing Management, 42 (5), 773-782.

Parker, G.G., Van Alstyne, M. W. \& Choudary, S.P. (2016) S. P. Plataforma: A Revolução da Estratégia, São Paulo: Editora HSM do Brasil.

Reuver de, M., Verschuur, E., Nikayin, F., Cerpa, N. \& Bouwman, H., 2015. Collective action for mobile payment platforms: a case study on collaboration issues between banks and telecom operators. Electronic Commerce Research and Applications, 14, 331-344. Recuperado em 29 de maio, 2020, de https://doi.org/10.1016/j.elerap.2014.08.004 Rochet, J.-C. \& Tirole, J., (2003, june). Platform competition in two-sided markets. Journal of the European Economic Association, 1, 990-1029. 
Rohlfs, J., (1974) Theory of Interdependent Demand for a Communications Services. Joumal Of Economics and Management Science, 5(1), 16-37.

Sebrae (2018). As Fintechs e os Pequenos Negócios. LAB - Laboratório de Inovação Financeira ABDE/BID/CVM. Recuperado em 20 de maio, 2020, de https://www.sebrae.com.br/Sebrae/Portal\%20Sebrae/Anexos/FintecsMPE 13.9.2018.pdf

Schumpeter J.A. (1934). The Theory of Economic Development. An Inquiry into Profits, Capital, Credit, Interest, and the Business Cycle. Harvard University Press: Cambridge, MA.

Souza, R. de (2020, ago). Pandemia impulsiona e-commerce e Brasil já tem mais de 1,3 milhão de lojas. Recuperado em 1 de dezembro, 2020 de https://canaltech.com.br/e-commerce/pandemia-impulsiona-e-commerce-e-brasilja-tem-mais-de-13-milhoes-de-lojas-170611/

Stabell, C.B. \& Fjeldstad, O.D., (1998) Configuring value for competitive advantage: on chains, shops, and networks. Strategic Management Journal. 19, 413-437.

Staykova, K. S. \& Damsgaard, J. (2015). The race to dominate the mobile payments platform: Entry and expansion strategies, Electronic Commerce Research and Applications, 14(5), 319-330.

Staykova, K.S.\& Damsgaard, J., (2016). Adoption of mobile payment platforms: managing reach and range. Journal of theoretical and applied electronic commerce research, 11, 65-84. Recuperado em 29 de maio, 2020, de https://doi.org/10.4067/S0718-18762016000300006

Storbacka, K. (2011). A solution business model: Capabilities and management practices for integrated solutions. Industrial Marketing Management, 40(5), 699-711.

Tauhata, S.(2020,jun). Pesquisa mostra que 55\% dos brasileiros tiveram redução de renda por pandemia. Valor.globo.com. Recuperado em 1 de dezembro, 2020, de

https://valor.globo.com/financas/noticia/2020/06/09/pesquisa-mostra-que-55percent-dos-brasileiros-tiveramreducao-de-renda-por-pandemia.ghtml

Thomas, L.D.W., Autio, E. \& Gann, D.M., (2014). Architectural leverage: putting platforms in context. Academy of Management Perspectives, 28, 198-219.

Van der Borgh, M., Cloodt, M. \& Romme, A.G.L., (2012). Value creation by knowledge-based ecosystems: evidence from a field study. R\&D Management. 42, 150-169.

Wallin, J., Chirumalla, K. \&Thompson, A., (2013). Developing PSS concepts from traditional product sales situation: the Use of Business Model Canvas. In: Meier, H. (Ed.), Product-Service Integration for Sustainable Solutions, Lecture Notes in Production Engineering. Springer Berlin Heidelberg, 263-274.

Weichert, M., (2017). The future of payments: how fintech players are accelerating customer- driven innovation in financial services, Journal of Payments Strategy \& Systems, 11(1), 23-33.

Williamson O.E. (1979). Transaction cost economics: the governance of contractual relations. Journal of Law and Economics, 22, 233-261.

Wirtz, B.W., Pistoia, A., Ullrich, S. \& Göttel, V. (2016). Business models: origin, development and future research perspectives, Long Range Planning, 49, (1) 36-54.

Yin, R. K. (2009), Case Study Research: Design and Methods. 4. ed. Thousand Oaks: Sage.

Ziouvelou, X. \& McGroarty, F. (2018).A business model framework for crowd-driven IoT ecosystems, International Journal of Social Ecology and Sustainable Development, 9 (3), 14-33.

Zott, C., Amit, R, \& Massa, L. (2011). The business model: recent developments and future research. Journal of Management, 37(4),1019-1042.

\footnotetext{
i O termo fintech (abreviação que designa financial technology), faz referência a empresas que utilizam a tecnologia para operar fora dos modelos tradicionais de negócio de serviços financeiros, buscando mudar a maneira que estes serviços são oferecidos (Fortnum et al.,2017), mais especificamente, por meio da comunicação, internet e o processamento automatizado da informação (Gabor \& Brooks, 2017).

ii $\mathrm{O}$ Paypal refere-se à característica de provedor de pagamentos digitais, e optou-se em todo texto descrevê-lo desta forma.

iii Falas do entrevistado em itálico reproduzidas por todo o corpo do caso.
} 